\title{
Monitoramento da qualidade e hidrogeoquímica das águas subterrâneas do setor noroeste da região metropolitana de Fortaleza CE
}

\author{
Letycia Oliveira Venancio $^{1^{*}}$ \\ Diolande Ferreira Gomes ${ }^{2}$ \\ George Satander Sá Freire ${ }^{2}$ \\ Inácio Ocinai de Lima Neto ${ }^{2}$ \\ ${ }^{1}$ Universidade Estadual de Campinas \\ UNICAMP \\ Instituto de Geociências \\ Departameto de Recursos Naturais \\ Rua Macedo Soares, 850 \\ Cidade Universitária \\ Campinas SP Brasil \\ CEP 13083-130 \\ ${ }^{2}$ Universidade Federal do Ceará - UFC \\ Departamento de Geologia \\ Laboratório de Geologia Marinha e Aplicada \\ Campus Universitário do Pici \\ Bloco 912/913 \\ Fortaleza CE Brasil \\ CEP 60455-970 \\ *Autora para correspondência \\ letycia.venancio@hotmail.com
}

\begin{abstract}
RESUMO
As ameaças antrópicas para a qualidade da água, como a acidificação e degradação de fontes subterrâneas, têm efeitos cumulativos, aumento dos custos de tratamento para a produção de água potável e podem levar a problemas de saúde humana e perdas econômicas. Com o intuito de aprofundar os conhecimentos sobre as águas subterrâneas em áreas urbanas, no tocante a qualidade e geoquímica, foi realizado um monitoramento em dez (10) poços localizados na Região Metropolitana de Fortaleza que abrangeu diferentes condições climáticas do Estado. As análises químicas foram realizadas no Laboratório de Geoquímica Ambiental da Universidade Federal do Ceará e os procedimentos de controle da qualidade da água para consumo humano foram executados com base na Portaria de Consolidação $n^{\circ} 5$ do Ministério da Saúde, de 28 de setembro de 2018,no Anexo XX. A especiação aquosa foi realizada com base no cálculo do índice de saturação (IS) das fases minerais hematita, goethita, caulinita e quartzo. No período de monitoramento, todos os resultados analíticos não ultrapassaram o valor máximo permitido para uso e consumo humano quanto aos elementos: alumínio, amônia, dureza, sulfato, fluoreto e nitrito. As águas são dominantemente do tipo cloretada-sódica, com nível de STD de águas doces. Os teores de nitrato revelam águas não contaminadas na maior porção da área, embora localmente há indícios de contaminação. A especiação aquosa utilizando Phreeqc demonstrou que as fases apresentam condições de supersaturação em 100\% nas composição óxido-hidróxido, indistintamente nos dois sistemas aquíferos. A composição aluminosa apresenta 66,67\% dos IS em condições de supersaturação (precipitação) e $33,33 \%$ em condições de subsaturação (dissolução). A composição silicosa apresenta 70,96\% dos IS em condições de supersaturação (precipitação) e 29,04\% em condições de subsaturação (dissolução). O monitoramento possibilitou o estabelecimento de propostas de estratégias de manejo sustentável do sistema aquífero e do uso das águas subterrâneas.
\end{abstract}

Palavras-chave: Monitoramento da Qualidade da Água; Águas Subterrâneas; Hidrogeoquímica; Geoquímica Analítica; Geoquímica Ambiental.

\section{ABSTRACT}

Anthropic threats to water quality, such as acidification and degradation of underground sources, have cumulative effects, increased treatment costs for the production of drinking water and can lead to human health problems and economic losses. In order to deepen the knowledge about groundwater in urban areas, with regard to quality and geochemistry, monitoring was carried out in ten (10) wells located in the Metropolitan Region of Fortaleza, which covered different climatic conditions of the State. Chemical analyzes were performed at the Environmental Geochemistry Laboratory of the Federal University of Ceará and the quality control procedures for water for human consumption were carried out based on Consolidation Ordinance No. 5 of Ministry of Health, of $28^{\text {th }}$ September 2018, in Annex XX. Aqueous speciation was performed based on the calculation of the saturation index (IS) of the mineral 
phases hematite, goethite, kaolinite and quartz. During the monitoring period, all analytical results did not exceed the maximum allowed value for human consumption regarding the elements: aluminum, ammonia, hardness, sulfate, fluoride and nitrite. The waters are predominantly of the chloride-sodium type, with STD level of fresh water. The contents of nitrate reveals uncontaminated water in the largest portion of the area, although locally there are signs of contamination. The aqueous speciation using Phreeqc demonstrated that the phases present $100 \%$ supersaturation conditions in the oxide-hydroxide composition, indistinctly in the two aquifer systems. The aluminous composition presents $66.67 \%$ of the SI under supersaturation conditions (precipitation) and $33.33 \%$ under subsaturation conditions (dissolution). The siliceous composition presents $70.96 \%$ of the SI under supersaturation conditions (precipitation) and $29.04 \%$ under subsaturation conditions (dissolution). The monitoring enabled the establishment of proposals for sustainable management strategies for the aquifer system and the use of groundwater.

Keywords: Water Quality Monitoring; Groundwater; Hydrogeochemistry; Analytical Geochemistry; Environmental Geochemistry.

\section{INTRODUÇÃO}

A disponibilidade e qualidade da água e governança da água estão, hoje, no centro da discussão sobre segurança hídrica. Quatro questões inter-relacionadas são dominantes na segurança da água: disponibilidade de água, vulnerabilidade humana a perigos e desastres, necessidades humanas (especialmente segurança alimentar) e sustentabilidade (COOK; BAKKER 2010).

Recursos hídricos limpos, confiáveis e sustentáveis são vitais para a sobrevivência e desenvolvimento humano. No entanto, devido ao desenvolvimento urbano, os corpos hídricos foram severamente poluídos e, atualmente, a deterioração da qualidade da água tornou-se um problema e desafio cada vez maior e sério no mundo inteiro (QU; ALVAREZ; LI, 2013).

Os estudos referentes à qualidade $\mathrm{e}$ química das águas subterrâneas abrangem a avaliação das concentrações relativas dos constituintes presentes e seus padrões de variabilidade, a fim de fazer prognósticos, investigar danos no manejo e reconhecer e/ou deduzir tendências de contaminações. Recentemente, tem-se visto o crescente aumento dos casos de contaminação das águas subterrâneas, associadas a: (i) anomalias naturais geoquímicas (dos elementos ferro, manganês, flúor e, secundariamente, cromo, bário e arsênio), devido à dissolução de minerais específicos; e (ii) atividades humanas contaminantes, relacionadas a áreas urbanas sem rede de esgoto ou com atividades industriais, armazenamento de produtos perigosos e deposição de resíduos sólidos (HIRATA; SUHOGUSOF, 2019).

A crescente demanda de água como resultado do aumento da taxa de crescimento da população, a necessidade de produção de alimentos e crescimento do setor industrial, aliado a deterioração qualitativa dos recursos hídricos superficiais, torna a água subterrânea um patrimônio de valor capaz de funcionar como reserva estratégica no desenvolvimento socioeconômico da comunidade.

O Brasil contém maior volume de água doce do que qualquer nação do mundo. No entanto, esse recurso natural essencial está ameaçado por aumentos rápidos no consumo de água e degradação de sua qualidade, principalmente como resultado de pressões antropogênicas (MELLO et al., 2020). Apesar disso, esse recurso natural está se tornando escasso por causa do aumento do consumo, secas prolongadas, distribuição precária, infraestrutura de tratamento inadequada $\mathrm{e}$ degradação da qualidade da água (VAL et al., 2019).

A diminuição da qualidade da água tornouse uma preocupação global à medida que as atividades antropogênicas se expandem e as mudanças climáticas ameaçam causar sérias alterações no ciclo da água (ABBOTT et al., 2019). A preocupação global é garantir suficiência na quantidade e qualidade de água para saúde pública, segurança alimentar, e demanda de acesso à água de boa qualidade para consumo (MELLO et al., 2020).

No semiárido brasileiro as águas armazena 
das nas rochas cristalinas apresentam geralmente elevado teor em sais, decorrente de vários fatores como o solo salino, evaporação elevada em relação a precipitação, falta circulação da água nas fraturas das rochas. Portanto, as águas doces encontradas nos terremos sedimentares, como nesta pesquisa, assumem um papel relevante no abastecimento, sendo necessário $\mathrm{o}$ acompanhamento da qualidade e reservas dessas águas para evitar prejuízos a sociedade.

A pesquisa foi realizada na Região Metropolitana de Fortaleza (RMF) situada na porção nordeste do estado do Ceará. O monitoramento da qualidade da água foi realizado para obtenção e integralização dos aspectos hidrogeológicos da área, quanto a qualidade e hidrodinâmica do aquífero, visando gerar informações para uma melhor proteção e aproveitamento racional dos

\subsection{CONTEXTO GEOLÓGICO LOCAL}

A fonte de água subterrânea diretamente poluída por filtração superficial (ou recarga) foi designada como a fonte primária de infiltração de contaminantes (IOP, 2019) dessa forma, o conhecimento do contexto 1 geológico e hidrogeológico do local

\subsubsection{FORMAÇÃO BARREIRAS}

Constituída litologicamente por sedimentos areno-argilosos, de espessura variável entre 20 e 50 metros, pouco ou não litificados, de coloração avermelhada, creme ou amarelada, muitas vezes com aspecto mosqueado $\mathrm{e}$ horizontes conglomeráticos e níveis lateríticos. Tais níveis não apresentam cota definida e podem estar associados à percolação da água

\subsubsection{COMPLEXO GNÁISSICO-MIGMATÍTICO}

Segundo Brandão (1995) o Complexo gnáissico-migmatítico, de posicionamento estratigráfico no Proterozóico Inferior, é a unidade que ocupa maior área de distribuição no âmbito da RMF. Representa uma sequência dominantemente paraderivada, constituída de gnaisses aluminosos, em parte migmatizados e frequentemente intercalados por níveis quartzíticos e carbonáticos. recursos naturais. Neste artigo a apresentação dos resultados e a discussão tentarão mostrar como a integração da disponibilidade de água, sua qualidade e governança podem ser fundamentais para a segurança hídrica das populações humanas locais.

Tendo em vista a necessidade fundamental que a água representa para as atividades coletivas na área, tornou-se imprescindível a avaliação da qualidade deste recurso, sua hidrodinâmica e condições de aproveitamento e manejo do mesmo. Os pontos de monitoramento e coleta estão localizados setor noroeste da RMF, no Campus Universitário do Pici, inserido na carta topográfica SA.24. Z-C-I-V da Folha Fortaleza, delimitada pelas coordenadas geográficas de 3 34' $16^{\prime \prime} .19$ a 3 $34^{\prime} 43^{\prime \prime} .49$ de Latitude Sul e de $38^{\circ} 34^{\prime} 03^{\prime \prime} .81$ a $38^{\circ} 34^{\prime}$ 42".71 Longitude Oeste (Figura 1).

amostrado possui grande importância nas delimitações de processos da interações águarocha. O contexto geológico local é constittuído pela a formação barreiras e o complexo gnáissico-migmatítico.

subterrânea que lixivia o elemento ferro, concentrando-o em determinados níveis (CAVALCANTE, 1998). A Formação Barreiras é a litologia predominante, em toda a área do Campus do Pici, onde repousam discordantemente sobre o embasamento cristalino.

Os litotipos são biotitas-gnaisses com ocorrência ou não de muscovita, anfibólio, quartzo, granada e sillimanita. De maneira geral, os gnaisses apresentam cor cinza clara, granulação fina a grossa com padrão retilíneo da foliação e os migmatíticos mostram diferentes feições deformacionais com contatos transicionais em relação às unidades sobrejacentes. 


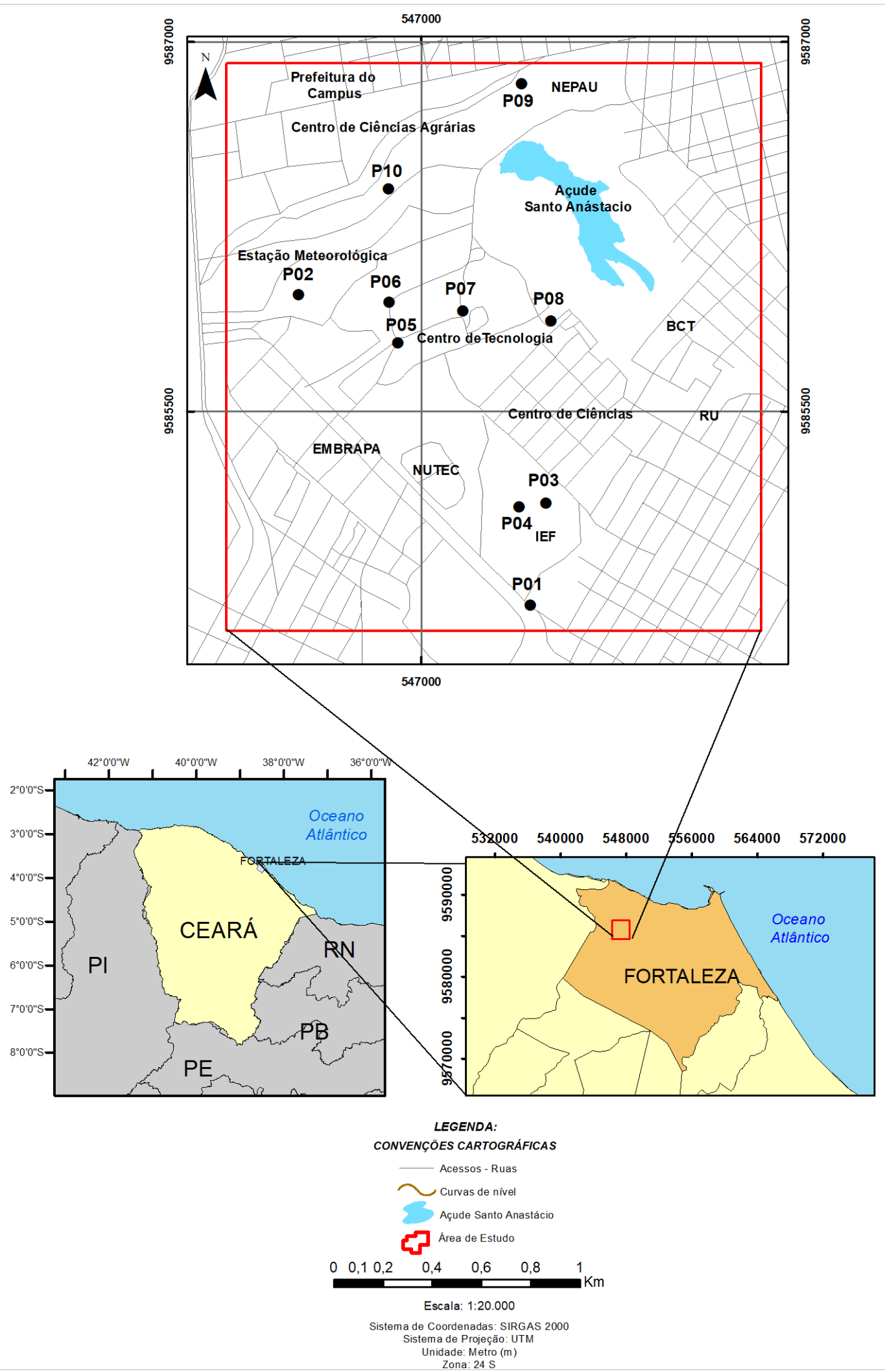

Figura 1

Mapa de localização da Área de Estudo. Fonte: Elaborado pelos autores. 


\subsection{CONTEXTO HIDROGEOLÓGICO LOCAL}

\subsubsection{SISTEMA HIDROGEOLÓGICO BARREIRAS}

Sedimentos tércio-quaternários da Formação Barreiras, composto por níveis areno-argilosos e/ou argilo-arenosos, com variação faciológica de cores variadas com predominância de coloração avermelhada. Possui granulação variando da fração argila até areia média, contendo níveis conglomeráticos intercalados aparecendo ocasionalmente.

$\mathrm{O}$ aquífero Barreiras recebe recarga direta das águas oriundas das precipitações pluviométricas e das águas dos riachos situados ao norte da área. Como exutórios, evidenciando-se a evapotranspiração, o açude

\subsubsection{SISTEMA HIDROGEOLÓGICO CRISTALINO}

Esse sistema compreende o embasamento cristalino alterado não aflorante, representado litologicamente pelas rochas gnáissicas do Complexo Ceará de idade Pré-Cambriana, composta por gnaisses e migmatitos, e intercalações de corpos lenticulares de anfibolitos, quartzitos e calcários subordinados (TORQUATO et al., 1989).

A compartimentação do aquífero é comumente associada com a elevação ou subsidência do embasamento hidrogeológico por falhas que muitas vezes aumentam ou diminuem a espessura saturada, afetando diretamente $\mathrm{o}$ volume das reservas hidrogeológicas (LUCENA et al., 2005). O sistema hidrogeológico cristalino é recarre-

\section{MATERIAIS E MÉTODOS}

O estudo contemplou a avaliação das concentrações relativas dos constituintes presentes e os seus padrões de variabilidade, objetivando realizar prognósticos e reconhecer disposições de contaminações.

A definição dos pontos de coleta desse trabalho foi efetuada a partir do reconhecimento da área de estudo, considerando os poços existentes na área, seus respectivos dados de perfil construtivo e litológico do poço, viabilidade de coleta e uso da água, somando assim um total de dez (10) poços para monitoramento com coletas periódicas de amostras de água subterrânea.

As variáveis físico-químicas das águas estão sujeitas a variações sazonais, por isto
Santo Anastácio e a lagoa Genibaú (GOMES, 2008).

Em Burazer et al. (2010) e Diaz et al. (2014) a litoestratigrafia e a estrutura geológica são fatores importantes que afetam a geometria do aquífero Barreiras, além de determinar as características hidrogeológicas. Dessa forma, a porosidade, a permeabilidade e o efeito das falhas (atuando como uma barreira que diminui a velocidade da água fluxo ou como conectores entre aquíferos) na transmissividade hidráulica são importantes parâmetros caracterizadores (PILLI et al., 2012).

gado através de precipitações pluviométricas por infiltração indireta, por meio dos sedimentos da Formação Barreiras e manto de alteração que retém as águas até que ocorra a infiltração nas fraturas abertas, funcionando como meio de transferência.

$\mathrm{O}$ armazenamento e o fluxo desse sistema ocorrem nas fraturas conectadas e espelhos d'água, superfície alterada e redes de drenagem. Os exutórios naturais são representados pela evapotranspiração, pelo açude Santo Anastácio e pela Lagoa Genibaú. Os exutórios artificiais pelos diversos poços (cerca de 40) usados na irrigação, abastecimento das piscinas, recreação, dessedentação animal, entre outros usos.

foram estudadas em diferentes períodos. Foram coletadas amostras nos meses de fevereiro, junho e dezembro de 2018 para análise físico-química completa, dos elementos maiores e menores. Em fevereiro de 2019 foi realizada mais uma amostragem desses poços para verificação, porque os poços P05 e P09 apresentaram mudanças bruscas na concen-tração de alguns dos parâmetros determinantes da qualidade,

As análises físico-químicas foram realizadas no Laboratório de Geologia Marinha e Aplicada, setor Geoquímica Ambiental, do Departamento de Geologia da UFC e seguiram os procedimentos analíticos descritos no Standard Methods for the Examination of 
Water and Wastewater (APHA, 2012). Os metais pesados foram determinados por ICP OES no Núcleo de Tecnologia e Qualidade Industrial do Ceará - NUTEC.

$\mathrm{Na}$ determinação da concentração de nitrogênio amoniacal total $\left(\mathrm{N}-\mathrm{NH}_{3,4}\right)$, pelo método Fenato, um composto de cor azul é formado pela reação da amônia com hipoclorito e fenol. O hipoclorito foi substituído por dicloisocianurato sódico dihidratado (DCI), conforme Aminot e Chaussepied (1983) e Aminot e Kérouel (2004), o qual permite maior estabilidade da solução.

A determinação de $\mathrm{N}^{-\mathrm{NH}_{3,4}}$ iniciou-se in situ com a adição das soluções de fenolnitroprussiato (R1) e solução alcalina complexante ao cloro (R2), imediatamente após a coleta e, no cálculo da concentração de $\mathrm{NH}_{3}$ (amônia não ionizada), foi usada a equação de Johansson e Wedborg (AMINOT; CHAUSSEPIED, 1983), a qual tem como variáveis o $\mathrm{pH}$, a temperatura e a salinidade da água, sendo o $\mathrm{pH}$ a variável mais importante.

Os parâmetros $\mathrm{pH}$, sólidos totais dissolvidos (STD), condutividade elétrica (CE) e fluoreto foram determinados usando sondas multiparâmetros de marca Thermo Scientific Orion, sendo a de modelo Star A329 Portable usada para determinar $\mathrm{pH}$, STD e CE e, a de modelo STAR A324 para o fluoreto. Nas medidas espectrofotométricas foi utilizado um espectrofotômetro Thermo Scientific modelo Evolution 300 UV-VIS e um fotômetro de chama de marca Analyser, modelo 910 para a determinação dos teores de sódio e potássio.

Para avaliar o controle da qualidade das análises químicas foi feito o balanço dos cátions e ânions, onde o somatório da concentração em meq/L dos cátions principais $\left(\mathrm{Ca}^{2+}, \mathrm{Mg}^{2+}, \mathrm{Na}^{+}, \mathrm{K}^{+}\right.$e $\left.\mathrm{Fe}\right)$ deve ser mais próxima possível da concentração dos ânions principais $\left(\mathrm{HCO}_{3}^{-}, \mathrm{SO}_{4}^{2-}, \mathrm{Cl}^{-}\right.$e $\left.\mathrm{F}^{-}\right)$. Para uma análise aceitável admite-se o erro máximo de $5 \%$.

A modelagem geoquímica com base no cálculo do índice de saturação (IS) foi realizada com Phreeqc versão 3.5.0 com banco de dados Wateq4f para o cálculo do índice de saturação das fases minerais escolhidas durante $o$ monitoramento. Os resultados da modelagem foram utilizados para identificar a origem dos íons nas águas subterrâneas da área e os processos geoquímicos ocorrentes. As fases minerais sólidas analisadas devem estar presentes no contexto geológico do aquífero, de forma a entender os processos de saturação ocorrentes nas mesmas por meio do índice de saturação.

Para a composição óxido-hidróxido de ferro foram analisados os IS de duas fases sólidas minerais: a hematita e a goethita. Para a composição aluminosa foi analisado o IS da fase sólida mineral caulinita. Para a composição silicosa foi analisado o IS da fase sólida mineral quartzo.

No desenvolvimento da pesquisa ainda foi utilizado Qualigraf para a geração dos Diagramas de Piper.

\section{RESULTADOS E DISCUSSÃO}

\subsection{HIDROGEOQUÍMICA DAS ÁGUAS SUBTERRÂNEAS}

\subsection{1 $\mathrm{pH}$}

As amostras analisadas apresentaram $\mathrm{pH}$ entre 5,98 e 8,66 (fevereiro/2018), 5,96 e 9,03 (junho/2018) e 5,27 e 8,76 (dezembro/2018). As médias mensais foram de 7,14; 6,80 e 7,64 para os respectivos períodos amostrados. A ampla variação nos valores de $\mathrm{pH}$ foi observada tanto espacialmente, sobretudo na campanha de junho de 2018 em que o menor valor foi 5,95 (poço P05) e o maior foi 9,03 (poço P10) como temporalmente. Para os poços P05 e P09 as águas estavam ácidas $(\mathrm{pH} \quad 6,45$ e 6,07 respectivamente) em junho de 2018 e alcalinas caso poço P09 que está vizinho a um poço com $3 \mathrm{~m}$ de diâmetro e totalmente aberto. No entanto, deve-se considerar que a mudança no
(pH 8,5) em dezembro de 2018 (Anexo).

Mudanças bruscas na qualidade da água são comumente verificadas em águas superficiais, devido à rápida reação tanto a fatores climáticos como antropogênicos. Já, no caso de águas subterrâneas, devido ao lento processo de infiltração, capacidade de absorção do solo, e interações com o meio, além de outros fatores, as mudanças na qualidade da água tendem a ser amortecidas, exceto em situações em que o poço seja raso e capte água de meio muito permeável, estando próximo a fontes poluidoras, como no sistema de amostragem do poço 09 , que passou de bailer, nas duas primeiras campanhas, para bombeamento, nas duas últimas, pode ter 
captado águas de outras formações e em maiores profundidades.

Notam-se variações nos valores de $\mathrm{pH}$ durante o período de estudo, podendo estas estar associadas as precipitações ocorrentes no período do monitoramento que podem ocasionar a diluição nos constituintes químicos da água armazenada no subsolo e concomitantemente introduzir elementos resultantes de atividades antrópicas depositados sobre o solo, como metais pesados, pesticidas, matéria orgânica, entre outros.

As amostragens ocorreram em um ano atipicamente chuvoso, visto que durante a quadra chuvosa (fevereiro a maio) a precipitação média foi de $1.035 \mathrm{~mm}$, enquanto a média histórica do Estado fica entre 505,6 e 695,8 mm, conforme FUNCEME (2019). Os valores de $\mathrm{pH}$ das amostras coletadas em junho são os mais influenciados pela recarga direta, visto que nos meses anteriores os índices pluviométricos foram elevados, e resultaram em

\subsubsection{CONDUTIVIDADE ELÉTRICA}

Os valores de condutividade elétrica das amostras de águas subterrâneas analisadas variaram de 127 a $1.422 \mu \mathrm{S} / \mathrm{cm}$ (fevereiro/2018), de 117,9 a $1.704 \mu \mathrm{S} / \mathrm{cm}$ (junho/2018), de 153,3 a $1.918 \mu \mathrm{S} / \mathrm{cm}$ (dezembro/2018) e de 104,8 a $2.584 \mu \mathrm{S} / \mathrm{cm}$ (setembro/2019). As amostras P05 e P09 foram coletadas em fevereiro de 2019, a fim de verificação e apresentam resultados de 1.343 e $1.457 \mu \mathrm{S} / \mathrm{cm}$, respectivamente. Esses dois poços são os que apresentaram as maiores flutuações nos valores de CE, indo de água doce em abril de 2019, quando o STD medido foi inferior a $500 \mathrm{mg} / \mathrm{L}$, a águas levemente salobras, em fevereiro de 2019, com STD em torno de $1.000 \mathrm{mg} / \mathrm{L}$.

As médias mensais foram de $575 \mu \mathrm{S} / \mathrm{cm}$, $816,4 \mu \mathrm{S} / \mathrm{cm}$ e $900,1 \mu \mathrm{S} / \mathrm{cm}$ para os respectivos períodos de estudo em que foram amostrados os 10 poços. Estes valores fornecem uma relação direta com a quantidade de sólidos totais dissolvidos existentes nessas águas, nas quais se observou que o STD $(\mathrm{mg} / \mathrm{L})$ foi cerca de 0,7 vezes o valor da $\mathrm{CE}(\mu \mathrm{S} / \mathrm{cm})$.

De acordo com Ribeiro (2001) os valores considerados mais baixos da condutividade elétrica ocorrem devido a pequenas variações químicas nos constituintes em solução, uma quadra chuvosa muito acima da média do Estado, como já citado acima.

O estudo de Gomes (2008) caracteriza o Campus pela predominância de águas ácidas, ou seja, $\mathrm{pH}$ menor que 7 , principalmente na parte leste e sul da área, com médias oscilando entre 5,$8 ; 6,1$ e 5,7 na primeira, segunda e terceira amostragens, respectivamente, o que demonstra uma concordância com o estudo. Neste estudo, predominam águas alcalinas na porção noroeste da área de estudo e águas ácidas principalmente na porção norte e sul da área, exceto na terceira amostragem na qual estas se apresentam mais alcalinas na porção norte. As águas ao redor do açude Santo Anastácio têm seu pH tornando-se mais ácido à medida que se afastam do corpo d'água.

Rose et al. (1979) demostram que as águas ácidas tendem a tornar a maioria dos metaistraços bastante solúveis, com no caso de $\mathrm{Zn}, \mathrm{Cd}$, $\mathrm{Hg}, \mathrm{Cu}, \mathrm{Ag}, \mathrm{Co}, \mathrm{Ni}, \mathrm{U}, \mathrm{V}$ e As. Já as águas alcalinas ou neutras favorecem a precipitação ou a adsorção dos metais.

enquanto que os maiores valores podem estar associados, em locais específicos, a maiores concentrações de íons, principalmente cloretos.

Os valores de condutividade são mais elevados na porção noroeste e menores na porção norte e sul da área. Os valores elevados são diretamente proporcionais às concentrações mais elevadas de íons cloreto.

Esperava-se que os valores de CE fossem diminuindo ao longo do tempo devido às chuvas ocorridas nos meses anteriores, mais de 1000 $\mathrm{mm}$, que se infiltram no terreno poroso até alcançarem o lençol freático causando a subida dos níveis da água e diluição dos sais. No entanto, observou-se que nos poços $\mathrm{P} 02, \mathrm{P} 03$, P04 e P06 os valores pouco flutuaram. Já nos poços P05, P07, P08, P09 e P10 a CE aumentou significativamente. Esse comportamento sugere movimento de água, induzido por bombeamento de diferentes zonas do aquífero, causando repentinas mudanças no teor de sais das águas.

As águas do sistema cristalino são geralmente salobras e as da Formação Barreiras são doces e, visto que os poços captam águas dos dois sistemas, há uma mistura de água, mas prevalece a água doce no Campus. 


\subsubsection{SÓLIDOS TOTAIS DISSOLVIDOS}

As amostras analisadas apresentaram concentrações de sólidos totais dissolvidos variando de 110 a $1.150 \mathrm{mg} / \mathrm{L}$ (fevereiro/2018), 97 a $1.122 \mathrm{mg} / \mathrm{L}$ (junho/2018) e 74 a 1.166 $\mathrm{mg} / \mathrm{L}$ (dezembro/2018). As médias mensais foram de 467, 416 e $538 \mathrm{mg} / \mathrm{L}$ para os respectivos períodos amostrados. As amostras P05 e P09 foram coletadas em fevereiro de 2019 para fins de verificação, com resultados de 804 e $1116 \mathrm{mg} / \mathrm{L}$ respectivamente.

Na primeira amostragem, nove das amostras apresentaram teores dentro do valor permitido de concentração de STD para águas potáveis, e apenas a amostra P02 estava fora. Na segunda

\subsubsection{ALCALINIDADE TOTAL}

A maioria das amostras (75\%) apresentou alcalinidade devido apenas à presença de bicarbonato, nas quais o $\mathrm{pH}$ esteve entre 5,9 e 7,9. Na campanha de dezembro as amostras apresentam águas mais alcalinas, devido a bicarbonato e carbonato. As águas subterrâneas com menor condutividade elétrica foram as que apresentam menor alcalinidade. Portanto, essas águas apresentam menor capacidade de suportar

\subsubsection{NITRATO}

O nitrato é um contaminante preocupante por estar muito difundido nos recursos hídricos subterrâneos e superficiais ao redor do mundo. A sua ocorrência em concentração elevada nas águas subterrâneas é dirigida por processos biogeoquímicos complexos, o que torna a avaliação da fonte um exercício complexo. É formado quer pelos processos naturais (fixação atmosférica, tempestades com raios) ou adicionado por meio de atividades antropogênicas (aplicações de fertilizantes, fossas sépticas) e entra na hidrosfera com facilidade (SHUKLA; SAXENA, 2020).

As amostras analisadas apresentaram teores de nitrato, em nitrogênio, variando de $<0,1$ a $12,5 \mathrm{mg} / \mathrm{L}$ (fevereiro/2018), 0,1 a $5,8 \mathrm{mg} / \mathrm{L}$ (junho/2018) e 0,1 a $8,23 \mathrm{mg} / \mathrm{L}$ (dezembro/2018). As médias mensais foram de 2,9; 1,7 e $1,8 \mathrm{mg} / \mathrm{L}$ para os respectivos períodos amostrados. As amostras coletadas em fevereiro de 2019, P05 e P09 apresentaram valores de 0,4 e $0,5 \mathrm{mg} / \mathrm{L}$ respectivamente.

e ocupação do solo (carga de nitrogênio no solo) afetando diretamente a qualidade das águas amostragem todas as amostras apresentaram valores dentro permitido para concentração de STD, exceto as amostra P10 e P09 na terceira amostragem.

Segundo a classificaçnao de Freeze and Cherry, 1979 (apud RICHTER; KREITLER, 1993) os poços P02 e P08 apresentaram águas levemente salobras (STD médio de 967 e 811 $\mathrm{mg} / \mathrm{L}$ respectivamente) e os poços $\mathrm{P} 01, \mathrm{P} 04$, P06 e P07, águas doces (STD $<500 \mathrm{mg} / \mathrm{L}$ ) nas três campanhas do monitoramento. Já os poços P03, P05, P09 e P10, dependendo do período de amostragem, podem apresentar águas doces ou levemente salobras.

alterações no $\mathrm{pH}$ que a tornariam mais ácidas. A alcalinidade não apresentou uma boa correlação com o $\mathrm{pH}(\mathrm{r}=0,57)$. Isso porque amostras de mesmo $\mathrm{pH}$ podem apresentar grande variação na alcalinidade, devido o teor de sais. Usualmente águas doces e pouco mineralizadas apresentam $\mathrm{pH}$ inferior a 6,5 (OTTAVIANI, 2007). Nesse estudo, há melhor correlação do $\mathrm{pH}$ versus $\mathrm{STD}$, com $\mathrm{r}=0,8$.

Em todas as campanhas as amostras do poço P03 foram as que apresentaram maior concentração de nitrato, entre 5,8 e $12,5 \mathrm{mg} / \mathrm{L}$. São valores preocupantes por que a partir de 5 $\mathrm{mg} / \mathrm{L}$ há suspeita de contaminação antrópica da água, como por exemplo por esgoto, fertilizante e resíduos de animais. O valor de $10 \mathrm{mg} / \mathrm{L} \mathrm{N}$ $\mathrm{NO}_{3}{ }^{-}$é o valor máximo permitido para águas potáveis no Brasil. O limite de nitrato $\left(\mathrm{NO}_{3}{ }^{-}\right)$ para águas destinadas ao consumo, no Brasil, é mais restritivo do que em outros países, como os da União Europeia e Nova Zelândia, que é de $50 \mathrm{mg} / \mathrm{L}$. Este valor expresso em nitrogênio corresponde a $11,3 \mathrm{mg} / \mathrm{L} \mathrm{N}^{-\mathrm{NO}_{3}}{ }^{-}$.

De acordo com Ecan (2019), se a água de abastecimento de uma comunidade atingir 5,65 $\mathrm{mg} / \mathrm{L}$ de nitrato, ou seja, a metade do valor permitido que é $11,3 \mathrm{mg} / \mathrm{L} \quad \mathrm{N}_{-} \mathrm{NO}_{3}$, um monitoramento adicional deve ser realizado. A contaminação de nitrato na área ocorre devido a três principais fatores, são eles: dinâmica do uso

penetrantes no aquífero; a ausência de um saneamento em algumas regiões de alta 
vulnerabilidade e a alta vulnerabilidade do sistema aquífero Barreiras. As maiores concentrações de nitrato nas águas subterrâneas do Campus ocorrem na porção norte da área.

Os resultados de Gomes (2008) para as águas subterrâneas do Campus do Pici mostram variação de 0,10 a $11,53 \mathrm{mg} / \mathrm{L}$ (primeira amostragem), 0,21 a 7,87 mg/L (segunda amostragem) e de 2 a $33 \mathrm{mg} / \mathrm{L}$ (terceira amostragem) nos poços analisados. A grosso modo e excluindo a concentração de $33 \mathrm{mg} / \mathrm{L}$, pode-se observar que a variação de nitrato na água, de 0,1 a 11,5 está de acordo com a encontrada atualmente, demonstrando estabilidade no nível de contaminação por nitrato nas águas do Campus do Pici, apesar do aumento da infraestrutura, atividades e

\subsubsection{SÓDIO E POTÁSSIO}

As amostras analisadas apresentaram teores de sódio variando de 27,0 a $198,7 \mathrm{mg} / \mathrm{L}$ (fevereiro/2018), $\quad 19,0$ a $319,9 \quad \mathrm{mg} / \mathrm{L}$ (junho/2018) e 23,1 a 253,5 $\mathrm{mg} / \mathrm{L}$ (dezembro/2018). As médias mensais foram de 94,$6 ; 129,4$ e $130,8 \mathrm{mg} / \mathrm{L}$ para os respectivos períodos amostrados. As amostras P05 e P09 foram coletadas em fevereiro de 2019, para fins de verificação, com resultados de 184,7 e 200,8 $\mathrm{mg} / \mathrm{L}$ respectivamente.

Na primeira campanha, todas as amostras apresentaram teores abaixo do valor permitido para consumo humano. As amostras P01, P08 e P10 apresentaram concentrações acima da máxima permitida na segunda e terceira campanhas. A amostra P09 apresentou concentrações acima da máxima permitida apenas na segunda campanha.

Segundo Fenzl (1986) o enriquecimento de sódio nas águas naturais é uma consequência da alta solubilidade dos sais de sódio e da boa mobilidade desse elemento. Durante o intemperismo e os processos de troca iônica $\left(\mathrm{Na}^{+}\right.$por $\left.\mathrm{Ca}^{+}\right)$grandes quantidades de sódio podem ser liberadas nas águas subterrâneas.

\subsubsection{DUREZA TOTAL}

A dureza da água pode variar geograficamente conforme a litologia que a água subterrânea percola e com a aqual mantem contato. Os principais sais responsáveis pela dureza são os de cálcio e magnésio e, devido a importante função biológica desses elementos,

Monarca et al. (2006) revisaram estudos epidemiológicos relatados no período 1979- quantidades de alunos nos últimos dez anos, que poderiam influenciam no aporte de contaminantes.

Todas as amostras apresentam concentrações de nitrito abaixo do limite de detecção $(0,001 \mathrm{mg} / \mathrm{L})$ em todas as amostragens, exceto a amostra P02 na terceira amostragem, com valor de 0,030 (dezembro/2018), estando assim todas as amostras dentro do valor máximo permitido $(1,0 \mathrm{mg} / \mathrm{L})$. Estes valores são aproximados e concordantes com o estudo de Gomes (2008) segundo o qual as amostras dos poços apresentaram médias de concentraçnao de nitrito de 0,02 $\mathrm{mg} / \mathrm{L}$ nas duas etapas de amostragens.

Em concordância com o monitoramento, em Gomes (2008) as águas subterrâneas do Campus do Pici mostraram variação das concentrações de sódio de 36,59 a 207,06 mg/L (primeira amostragem), de 22,46 a 176,92 mg/L (segunda amostragem) e de 9 a $152 \mathrm{mg} / \mathrm{L}$ (terceira amostragem) para os poços analisados.

Os teores de potássio variaram de 3,1 a 17,5 $\mathrm{mg} / \mathrm{L}$ (fevereiro/2018), 3,3 a 20,3 $\mathrm{mg} / \mathrm{L}$ (junho/2018) e 3,8 a $35,7 \mathrm{mg} / \mathrm{L}$ (dezembro/2018). As médias mensais foram de 8,7, 10,4 e $14,2 \mathrm{mg} / \mathrm{L}$ para os respectivos períodos amostrados. As amostras P05 e P09 foram coletadas em fevereiro de 2019 para fins de verificação, apresentando resultados de 15,7 e $23,9 \mathrm{mg} / \mathrm{L}$ respectivamente. Estes teores correspondem à liberação deste elemento, juntamente com o sódio, por meio do processo de intemperismo das rochas, que é facilmente adsorvido pelas argilas participando da formação de minerais secundários. No entanto, valores elevados de potássio podem ser provenientes do uso de fertilizantes químicos no solo para enriquecê-lo com nutrientes (como o nitrogênio-fósforo-potássio).

várias pesquisas foram realizadas para avaliar os efeitos da dureza da água potável sobre a saúde. Os primeiros estudos datam da década de 50, nos quais foi demonstrada uma relação inversa entre a dureza da água e doenças cardiovasculares (OTTAVIANI, 2007).

2004, atribuindo um importante papel na saúde à presença de magnésio na água. Resultados de 
estudos in vitro, em animais e humanos também são relatados como confirmação desta hipótese.

A dureza total variou de 18 a $256 \mathrm{mg} / \mathrm{L}$ (fevereiro/2018), 22 a $280 \mathrm{mg} / \mathrm{L}$ (junho/2018) e 10 a $288 \mathrm{mg} / \mathrm{L}$ (dezembro/2018). As médias mensais foram de 92,116 e $111 \mathrm{mg} / \mathrm{L}$ para os respectivos períodos amostrados. As amostras P05 e P09, também coletadas em fevereiro de 2019, apresentaram valores de 216 e $274 \mathrm{mg} / \mathrm{L}$ respectivamente.

De acordo com a $\mathrm{PC} \mathrm{n}^{0} 5$ de 28 de setembro de 2018 o padrão de potabilidade para dureza é de $500 \mathrm{mg} / \mathrm{L}$. Desta forma, quanto ao parâmetro dureza, as águas estudadas não oferecem risco à saúde. $O$ cálcio e o magnésio são essenciais para a saúde humana. A ingestão diária recomendada de cada elemento é definida em nível nacional e internacional (THOMAS, 2010). Um estudo da Organização Mundial da Saúde para discutir os nutrientes na água potável concentrou suas considerações no cálcio e magnésio, para os quais, ao lado do flúor, há evidências de benefícios à saúde associados com sua presença na água potável (OMS 2005).

A ingestão inadequada de cálcio foi associada a riscos aumentados de osteoporose, nefrolitíase (cálculos renais), câncer colorretal, hipertensão e acidente vascular cerebral, doença arterial coronariana, resistência à insulina e obesidade (BARTRAM, 2009). Embora o cálcio possa interagir com ferro, zinco, magnésio e fósforo dentro do intestino, reduzindo assim a absorção desses minerais, os dados disponíveis não sugerem que esses elementos se esgotem quando os humanos

\subsubsection{CLORETOS E SULFATOS}

Os teores de cloreto variaram de 26,3 a 280,0 $\mathrm{mg} / \mathrm{L}$ (fevereiro/2018), 23,0 a 306,3 mg/L (junho/2018) e 24,6 a 265,9 mg/L (dezembro/2018). As médias mensais foram de 105,7, 131,6 e $121,7 \mathrm{mg} / \mathrm{L}$ para os respectivos períodos amostrados. As amostras P05 e P09 foram coletadas em fevereiro de 2019 para fins de verificação, com resultados de 229,9 e 138,0 $\mathrm{mg} / \mathrm{L}$ respectivamente.

$\mathrm{Na}$ primeira amostragem as amostras $\mathrm{P} 02 \mathrm{e}$ P10 apresentaram valores acima da concentração máxima permitida, bem como as amostras P05 e P01, da segunda campanha e a amostra P10, da terceira.

A ocorrência de maiores concentrações de águas cloretadas na área está potencialmente

Diferentemente dos cloretos, os sulfatos apresentaram uma reduzida participação no teor consomem dietas contendo cálcio acima dos níveis recomendados (BARTRAM, 2009).

Estudos confirmam o papel fimportante e essencial que o magnésio desempenha na prevenção de doenças cardiovasculares (DEL GOBBO et al., 2013; CHIUVE et al., 2013). Um teor adequado de magnésio é vital na prevenção da aterogênese e da coagulação inadequada, mantendo o tônus vascular, o equilíbrio eletrolítico e uma série de outros processos celulares, bioquímicos e fisiológicos cruciais para a função cardiovascular e saúde (ROSANOFF, 2012).

O decreto-lei de Portugal, ${ }^{\circ}$ 306/2007, nas notas 2, 3 e 4, recomenda que a dureza total da água potável esteja entre 150 e $500 \mathrm{mg} / \mathrm{L}$, não sendo recomendada a concentração de cálcio acima de $100 \mathrm{mg} / \mathrm{L} \mathrm{e}$, acima de $50 \mathrm{mg} / \mathrm{L}$ para o magnésio (APDA, 2012; DIÁRIO DA REPÚBLICA, 2017).

No estudo de Gomes (2008), a análise da dureza de 40 amostras de água subterrânea variou de 27,44 a 188,16 mg/L (primeira amostragem), 19,40 a $112,52 \mathrm{mg} / \mathrm{L}$ (segunda amostragem) e 20,00 a $140,00 \mathrm{mg} / \mathrm{L}$ (terceira amostragem) nos poços amostrados, em concordância com o estudo em questão.

Os teores de magnésio variam de 3,8 a 51,4 $\mathrm{mg} / \mathrm{L}$ (fevereiro/2018), 4,8 a $50,9 \quad \mathrm{mg} / \mathrm{L}$ (junho/2018) e 0,5 a 44,2 mg/L (dezembro/2018). As médias mensais foram de 17,8, 20,9 e $19,6 \mathrm{mg} / \mathrm{L}$ para os respectivos períodos amostrados. As amostras P05 e P09 foram coletadas em fevereiro de 2019 para fins de verificação, com resultados de 39,8 e $45,6 \mathrm{mg} / \mathrm{L}$ respectivamente.

relacionada às águas pluviais que se infiltram através do solo, lixiviando os sais do solo e à evaporação que favorece a concentração dos sais nas águas superficiais que interagem com os aquíferos livres.

Nas águas superficiais as principais fontes do elemento cloreto são as descargas de esgotos sanitários (CETESB, 2016). Portanto, os cloretos presentes nas águas subterrâneas de aquíferos porosos também podem ter uma origem antrópica. Porém, no caso da água subterrânea do Campus do Pici, com exceção da amostra captada pelo poço 03, a amostra apresenta nível muito baixo de nitrato, sugerindo a não haver contaminação por esgoto urbano.

de sais das amostras. Os teores variaram de 0,5 a $86,6 \mathrm{mg} / \mathrm{L}$ (fevereiro/2018), 0,5 a 52,0 mg/L 
(junho/2018) e 0,1 a $52,8 \mathrm{mg} / \mathrm{L}$ (dezembro/2018). As médias mensais foram de 16,6, 14,9 e $14,7 \mathrm{mg} / \mathrm{L}$ para os respectivos períodos amostrados. As amostras P05 e P09 foram coletadas em fevereiro de 2019 para fins de verificação, com resultados de 15,1 e 28,7 $\mathrm{mg} / \mathrm{L}$, respectivamente.

As amostras P02 e P08 de águas levemente salobras apresentaram, nas três campanhas, diferentes correlações com a concentração de sulfato. As amostras P02 apresentam as maiores

\subsubsection{FLUORETO E SÍLICA}

Os teores de fluoreto nas amostras analisadas variaram de 0,20 a $1,00 \mathrm{mg} / \mathrm{L}$ (fevereiro/2018), 0,30 a $0,70 \mathrm{mg} / \mathrm{L}$ (junho/2018) e 0,08 a $0,60 \mathrm{mg} / \mathrm{L}$ (dezembro/2018). As médias foram $0,60,0,40$ e 0,20 para os períodos amostrados. As amostras P05 e P09 também coletadas em fevereiro de 2019 apresentaram 0,30 e $0,40 \mathrm{mg} / \mathrm{L}$ de fluoreto respectivamente.

O flúor em baixos teores, até $1,50 \mathrm{mg} / \mathrm{L}$, é benéfico à saúde, na prevenção de cáries dentárias de crianças e, acima deste teor, já é prejudicial, causando manchas nos dentes, conhecida como fluorose dentária. Quanto a esse parâmetro, as águas estudadas não oferecem risco à saúde. Quanto ao uso na

\subsubsection{FERRO TOTAL}

Os teores de ferro total nas amostras analisadas variam de 0,20 a $1,70 \mathrm{mg} / \mathrm{L}$ (fevereiro/2018), $\quad 0,10$ a $\quad 0,80 \quad \mathrm{mg} / \mathrm{L}$ (junho/2018) e 0,06 a $0,43 \mathrm{mg} / \mathrm{L}$ (dezembro/2018). As médias mensais foram de 0,60, 0,20 e $0,20 \mathrm{mg} / \mathrm{L}$ para os respectivos períodos amostrados. As amostras P05 e P09, coletadas também em fevereiro de 2019 apresentarem 4,00 e $0,20 \mathrm{mg} / \mathrm{L}$ de ferro respectivamente.

Tendo como referência o padrão $0,3 \mathrm{mg} / \mathrm{L}$ de ferro para águas destinadas ao consumo, podese observar que na primeira campanha as águas estavam mais enriquecidas em ferro e com alguns valores superiores a 0,30 . Quanto ao uso na irrigação, as águas são adequadas visto que o

\subsubsection{ALUMÍNIO}

Atualmente, a avaliação de risco à saúde, ou seja, avaliação de consequências esperadas como resultado da exposição a qualquer substância perigosa ou efeito perigoso, é um dos problemas médico-ecológicos essenciais. Até concentrações de sulfato e as P08, concentrações semelhantes às amostras de água doce. Isso demonstra que o sulfato nem sempre tem uma relação direta com a salinidade da água (STD ou CE). Todas as amostras encontram-se dentro do limite de concentração permitido para a consumo humano e dessedentação animal, cujos VMPs são, $250 \mathrm{mg} / \mathrm{L}$ e $1.000 \mathrm{mg} / \mathrm{L}$, respectivamente, conforme Resolução CONAMA N ${ }^{\circ} 396 / 2008$.

irrigação, o valor máximo permitido é mais restritivo - $1 \mathrm{mg} / \mathrm{L}$ (Resolução CONAMA 396/2008), mas esse uso é também adequado para as águas estudadas por não excedem esse limite.

Os teores de sílica variam de 9,0 a $54,5 \mathrm{mg} / \mathrm{L}$ (fevereiro/2018), 9,7 a 58,5 mg/L (junho/2018) e 6,2 a $55,2 \mathrm{mg} / \mathrm{L}$ (dezembro/2018). As médias mensais foram de 26,0 31,2 e 25,7 mg/L para os respectivos períodos amostrados. As amostras P05 e P09 foram coletadas em fevereiro de 2019 para fins de verificação, com resultados de 19,2 e $23,3 \mathrm{mg} / \mathrm{L}$, respectivamente. Neste ambiente a solubilidade da sílica é baixa e é produto do intemperismo de silicatos.

valor máximo permito é de $5 \mathrm{mg} / \mathrm{L}$, conforme Resolução do CONAMA No 396/2008.

Na campanha de fevereiro de 2019 o poço 05 apresentou um valor anômalo de ferro de 4,00 $\mathrm{mg} / \mathrm{L}$ que resultou na elevada turbidez da água, de 102,0 NTU, enquanto os valores normais de turbidez foram entre 5,0 e 19,0 NTU. Estes valores acima da média amostral, para o período estudado, são sinais de que o poço está com problemas nos seus componentes e, portanto, precisa passar por manutenção para limpeza dos filtros, por exemplo, para evitar que ele alcance um estágio de deterioração avançado que irá gerar custos altíssimos de reparo, se não o encerramento das atividades.

recentemente, considerava-se que o alumínio era inofensivo para pessoas, animais e plantas. É o terceiro mais abundante na crosta terrestre $(8,8 \%)$ depois do oxigênio e do silício, e o mais 
amplamente difundido entre os metais (MOMOT; BORIS, 2005).

Nessa pesquisa, os teores de alumínio variaram de 0,02 a $0,05 \mathrm{mg} / \mathrm{L}$ (junho/2018) e $0,02 \mathrm{mg} / \mathrm{L}$ (dezembro/2018). As médias mensais foram de 0,03 e $0,02 \mathrm{mg} / \mathrm{L}$ para os respectivos períodos amostrados. As amostras P05 e P09 foram coletadas em fevereiro de 2019 para fins de verificação, com resultados de 0,19 e $0,02 \mathrm{mg} / \mathrm{L}$ respectivamente. Todas as amostras encontram-se dentro da concentração permitida, em todo o período do monitoramento e, com raras exceções, o alumínio foi detectado apenas nas amostras com pH ácido, entre 5,27 e 6,53 .

\subsubsection{TURBIDEZ}

As amostras analisadas apresentaram turbidez variando de 13,0 a 19,0 NTU (fevereiro/2018), 6,5 a 17,9 NTU (junho/2018) e 4,7 a 9,4 NTU (dezembro/2018). As médias mensais foram de 15,$1 ; 12,3$ e 6,0 NTU para os respectivos períodos amostrados. As amostras P05 e P09 foram coletadas em fevereiro de 2019 para fins de verificação, com resultados de 102,0 e 2,9 NTU respectivamente. As amostras P02, P03 e P08 (terceira amostragem) estão dentro do valor máximo permitido de turbidez.

De acordo com Gomes (2008), os valores de turbidez nas águas dos poços do Campus do Pici oscilaram entre de 0,23 a 53,60 NTU na primeira amostragem (junho/julho de 2005), 0,28 a 1000 NTU na segunda amostragem (novembro/2005 e janeiro/2006) e de 2 a 27 NTU

\subsubsection{METAIS PESADOS}

Os metais pesados causam efeitos prejudiciais em plantas, animais e humanos como resultado de longo prazo ou exposição aguda. A toxicidade de metais pesados está aumentando devido à ampla liberação industrial, fontes agrícolas, químicas, domésticas e tecnológicas, que por sua vez contaminam a água, o solo e o ar (APRILE; DE BELLIS, 2020).

A biodisponibilidade é um fator importante na determinação da toxicidade dos metais. Em sistemas aquáticos, a biodisponibilidade do metal depende das características locais da água e dos sedimentos e, portanto, os riscos são específicos do local. A biodisponibilidade de metais é um fenômeno complexo, controlado por muitos processos. Vários fatores, incluindo $\mathrm{pH}$, conteúdo de carbono orgânico, dureza da água, alcalinidade,
Rondeau et al. (2008) examinaram as associações entre o consumo de água potável com alumínio por pessoas idosas e o declínio cognitivo, e concluiram que este declínio é maior nos indivíduos com maior ingestão de água com alumínio, porém o declínio é reduzido com a adição de sílica.

Em Gomes (2008) as águas subterrâneas do Campus do Pici apresentaram concentrações de alumínio entre $0,01 \mathrm{mg} / \mathrm{L}$ e $0,42 \mathrm{mg} / \mathrm{L}$ (primeira amostragem) e 0,01 a $0,31 \mathrm{mg} / \mathrm{L}$ (segunda amostragem), estando, portanto, com alguns valores acima do valor máximo permitido, e acima dos encontrados nesta pesquisa.

na terceira amostragem (novembro/2008). Observa-se, no estudo de Gomes (2008), uma variabilidade nos valores muito maior do que o encontrado neste estudo.

A turbidez de 102,0 NTU na água do poço P05, registrada em fevereiro de 2019, já foi explicada quando se falou do ferro, e foi considerado um valor anômalo causado por problemas no funcionamento do poço. Portanto os valores representativos deste poços são os da coletas anteriores, os quais estão entre 5,0 e 16,0 NTU. Segundo VILAGINÈS (2003), quando sabemos que a maioria das substâncias tóxicas, tanto inorgânicas quanto orgânicas, são adsorvidas, $90 \%$ em média, sobre o material em suspensão e coloides, entendemos a importância da turbidez.

oxigênio dissolvido e sulfetos, influenciam na especiação e biodisponibilidade de metais (LUOMA; RAINBOW, 2008).

Dos metais pesados, micropoluentes inorgânicos, geralmente presentes nas águas subterrâneas em concentrações traços, foram determinados os elementos bário, cromo, cobre, manganês, níquel, chumbo e zinco, e destes, apenas o chumbo foi detectado, em duas amostras, com valores acima do máximo permitido para consumo humano. Esses são os primeiros dados sobre metais pesados nas águas subterrâneas do campus universitário do Pici, não havendo, portanto, valores para avaliar a tendência.

Nascimento e Barbosa (2005) relatam que a contaminação por chumbo "pode levar a problemas de audição, alteração de 
crescimento, desenvolvimento cerebral deficiente, redução na síntese de vitamina $D, o$ que diminui a produção de hemoglobina, enfraquecendo o sistema imunológico, provocando dores nos músculos, nas articulações, elevação da pressão arterial, infertilidade, convulsões e perda de memória".

O cromo não foi detectado em nenhuma amostra e o zinco apresentou concentração entre $<0,5$ e $120,3 \mu \mathrm{g} / \mathrm{L}$. O cromo, assim como o chumbo, é um elemento indesejável na água por ser tóxico mesmo em concentrações traço, já o zinco, é essencial à saúde humana, e entre seus benefícios está a contribuição para o funcionamento normal do sistema imunológico. A água potável contém certas quantidades de zinco, que podem ser maiores quando armazenadas em tanques de metal. $\mathrm{O}$ zinco ocorre naturalmente no ar, água e solo, mas as concentrações de zinco estão aumentando de forma não natural, devido à adição de zinco às atividades humanas (ARPAT, 2007).

Excetuando-se os poços P09 e P10, observase baixas concentrações de $\mathrm{Pb}$ nas águas estudadas, relacionando isto à pequena mobilidade geoquímica do chumbo. A presença deste elemento nas águas coletadas pode estar associada a fontes antropogênicas ou mesmo à contaminação atmosférica. Assim, o monitoramento da qualidade da água desses poços torna-se de grande importância para a estimativa de fontes que podem vir a expor a comunidade à contaminação por este elemento traço.

\subsection{QUALIDADE DAS ÁGUAS SUBTERRÂNEAS E USOS PREPONDERANTES}

O histórico da degradação da água qualidade mostra uma deterioração contínua, com complexidade crescente principalmente no século 20 e com impactos cumulativos na saúde humana. A poluição pode prejudicar a disponibilidade de água em muitas regiões, aumentando a vulnerabilidade das populações humanas; o impacto econômico da degradação da qualidade da água pode ser contabilizado como o aumento nos custos de tratamento, ou o impacto na vida humana saúde ou perda de biodiversidade (TUNDISI et al., 2015).

As ameaças humanas à qualidade da água, como a eutrofização acidificação, sedimentação de águas superficiais, degradação de fontes subterrâneas e POPS (poluentes orgânicos persistentes), têm efeitos cumulativos, aumentam os custos de tratamento de água para produzindo água potável e pode acarretar diversos problemas de saúde humana e prejuízos econômicos (TUNDISI et al., 2015).

\subsubsection{CONSUMO HUMANO - CONTROLE E VIGILÂNCIA DA QUALIDADE DA ÁGUA}

Para controle da potabilidade investigou-se os parâmetros de acordo com a legislação pertinente a fim de se fazer prognósticos, investigar danos e observar as atividades que influenciam no meio estudado. Para efeito de comparação com a Portaria de Consolidação $\mathrm{N}^{\circ} 5$ do Ministério da Saúde, de 28 de setembro de 2017 (PC), no Art. 129 com Anexo XX, que dispõe sobre o controle e a vigilância da qualidade da água para consumo humano e seu padrão de potabilidade, a Tabela 1 apresenta os resultados para as águas subterrâneas amostradas.

O uso da água para consumo humano de alguns poços de estudo está comprometido, principalmente, devido aos elementos $\mathrm{Cl}, \mathrm{Fe}$ e $\mathrm{Na}$, que excedem os VMP com maior frequência e, no caso do $\mathrm{Cl}$ e $\mathrm{Na}$, elevam os STD a níveis de água salobra (Tabela 1). Dentre os poços pode-se dizer que aqueles que têm o teor de Fe como restrição ao uso, a qualidade pode ser aceitável visto que de acordo com a portaria vigente os valores deste elemento acima de $0,3 \mathrm{mg} / \mathrm{L}$ são aceitos desde que estejam complexados a produtos químicos de baixo risco à saúde e a concentração não ultrapasse $2,4 \mathrm{mg} / \mathrm{L}$.

A turbidez, apesar de exceder em quase $100 \%$ os VMP, pode ser reduzida fazendo a manutenção dos poços e limpeza dos filtros (Tabela 2). A contaminação antrópica, indicada pelo nitrato, é observada de forma pontual, em apenas um poço, mas deve-se identificar a fonte de poluição e eliminá-la para evitar uma contaminação disseminada no aquífero. 
Tabela 1 - Padrões organolépticos de potabilidade (Origem: PRT MS / GM 2914/2011, Anexo 10 - Atualização: Portaria de Consolidação $N^{\circ} 5$ de 28/08/2017 Art. 129, Anexo XX e percentagem de amostras em conformidade com a legislação. Fonte: Autores, de acordo com o Anexo 10 do Anexo XX da Portaria da Consolidação N`5 de 28 de setembro de 2017 . Valores em mg/L exceton para turbidez (NTU)

\begin{tabular}{lcccc}
\hline Parâmetro (mg/L) & VMP & $\mathbf{\% ( f e v / 1 8 ) *}$ & $\mathbf{\%}(\mathbf{j u n} / \mathbf{1 8})$ & $\mathbf{\%}(\mathbf{d e z} / \mathbf{1 8})$ \\
\hline Alumínio & 0,2 & 100 & 100 & 100 \\
Cloreto & 250 & 80 & 77,7 & 90 \\
Amônia (como NH 3 ) & 1,5 & 100 & 100 & 100 \\
Dureza Total & 500 & 100 & 100 & 100 \\
Ferro & 0,3 & 50 & 77,7 & 80 \\
Sódio & 200 & 100 & 66,6 & 60 \\
Sólidos Totais Dissolvidos & 1000 & 90 & 88,8 & 90 \\
Sulfato & 250 & 100 & 100 & 100 \\
Turbidez (NTU) & 5 & 0 & 0 & 30 \\
\hline \multicolumn{1}{c}{ Espécies químicas que representam risco à saúde (anexo 7)** } & \\
\hline Chumbo & 0,01 & 0 & 0 & 25 \\
Fluoreto & 1,5 & 90 & 100 & 100 \\
Nitrato (como N) & 10 & 90 & 100 & 90 \\
Nitrito (como N) & 1 & 100 & 100 & 100 \\
\hline número de amostras & & 10 & 9 & 8 para Pb \\
\hline
\end{tabular}

VMP: valor máximo permitido; *porcentagem que está dentro do valor máximo permitido; ${ }^{\star \star}$ Padrão de Potabilidade para substâncias químicas que representam risco à saúde (Origem: PRT MS/GM 2914/2011, Anexo 7).

Tabela 2 - Parâmetros de qualidade de água em desacordo com a legislação para as amostras analisadas.

\begin{tabular}{lcc}
\hline POÇOS & PARÂMETROS & USO PERMITIDO* \\
\hline P01 & Ferro e turbidez & Agricultura e irrigação \\
P02 & Cloreto, sódio, turbidez e STD & Agricultura e irrigação \\
P03 & Nitrato e turbidez & Agricultura e irrigação \\
P04 & pH e turbidez & Agricultura e irrigação \\
P05 & Cloreto, Ferro e turbidez & Agricultura e irrigação \\
P06 & Ferro e turbidez & Agricultura e irrigação \\
P07 & Turbidez & Agricultura e irrigação \\
P08 & Sódio, cloreto, ferro e turbidez & Agricultura e irrigação \\
P09 & Chumbo, sódio, pH, STD, ferro e turbidez & Agricultura e irrigação \\
P10 & Chumbo, sódio, cloreto, STD, turbidez & Agricultura e irrigação \\
\hline *Uso permitido sem tratamento prévio para a agricultura e irrigação, porém, para \\
consumo humano será necessário tratamento adequado.
\end{tabular}

\subsection{TIPOLOGIA QUÍMICA E CLASSIFICAÇÃO IÔNICA}

Dentre os cátions maiores, o dominante em todas as 31 amostras foi o sódio, cuja concentração variou de 21 a $320 \mathrm{mg} / \mathrm{L}$. Na primeira campanha (fevereiro de 2018) não foram observados valores acima de $200 \mathrm{mg} / \mathrm{L}$, mas, nas amostragens seguintes, junho e dezembro, nos poços P02, P08, P09 e P10 as concentrações ficaram entre 211 e $320 \mathrm{mg} / \mathrm{L}$.

Quanto aos ânions, em cerca de $65 \%$ das amostras o cloreto dominou, e no restante o bicarbonato. Isso resultou em dois tipos de água, as cloretadas sódicas e as bicarbonatadas sódicas, sendo que o tipo $\mathrm{Cl}-\mathrm{Na}$ foi mais abundante (Figura 2). Águas Cloretadas são o tipo mais comum no Estado, sendo observadas águas bicarbonatadas, as quais são comumente associadas a águas jovens, com maior frequência nas aluviões do baixo Jaguaribe (MOURA, 2013; GOMES, 2005) 


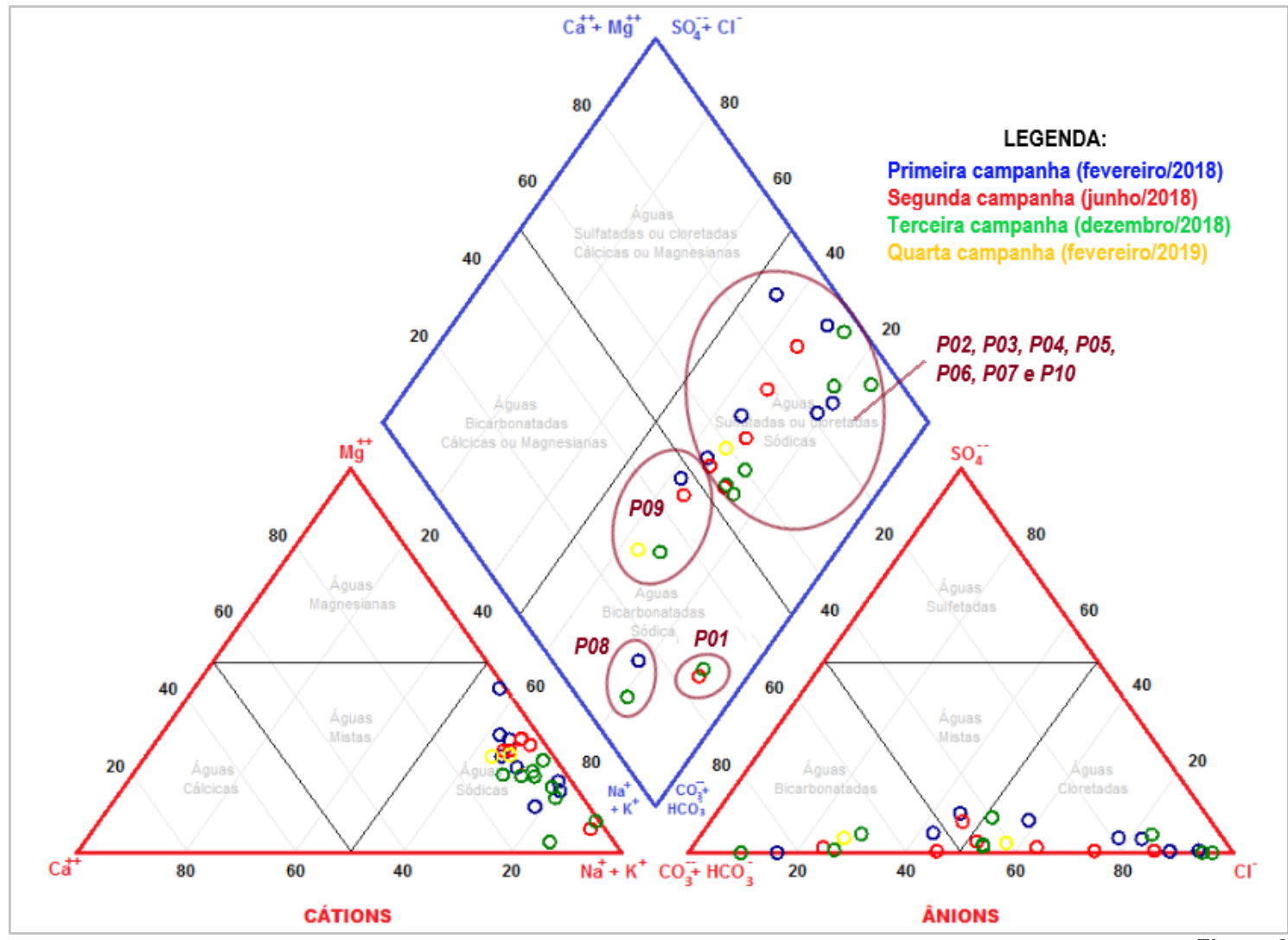

Figura 2

Diagrama de Piper para as quatro (4) campanhas amostrais do período de estudo. Fonte: autores.

\subsection{PRODUTIVIDADE AQUÍFERA}

Utilizou-se os parâmetros hidrodinâmicos capacidade específica e a vazão dos poços amostrais para a classificação das unidades seguindo a metodologia proposta por Struckmeier e Margat (1995) (Tabela 3). Com base na vazão, os poços P05, P09 e P10, enquadram-se na Classe 4, a qual é caracterizada por uma produtividade geralmente baixa, porém localmente moderada, onde os fornecimentos de água conseguem suprir abastecimentos locais ou consumo privado. Já os poços P01, P02, P03, P04, P06, P07 e P08 enquadra-se na Classe 5, de produtividade muito baixa, porém localmente a

\subsection{MODELAGEM GEOQUÍMICA COM PHREEQC}

Para a determinação do índice de saturação (IS) o programa Phreeqc efetuou cálculos da concentração molar, atividade iônica e do coeficiente de atividade das espécies químicas na água subterrânea nos pontos amostrais analisados. Em seguida obteve-se os valores do índice de saturação (IS) da fase sólida dos produtividade pode ser baixa e o abastecimento a partir desses poços é restrito uso de bombas manuais.

Com base na capacidade específica, o poço P02 apresenta produtividade alta de classe (2) e o P10 com produtividade moderada de classe (3). Os poços P03, P05 e P06 foram classificados com produtividade baixa, de classe (4) e os poços P07, P08 e P09 com produtividade muito baixa, de classe (5). O poço P01 foi classificado como pouco produtivo com abastecimento restrito a uso de bombas manuais, de classe (6).

minerais em equilíbrio com a solução aquosa nos dez (10) poços amostrados (Tabela 4).

A condição de supersaturação das espécies químicas, quando os valores de IS são positivos, apresenta uma possibilidade de formação da fase sólida mineral a partir da solução aquosa através de uma reação química inversa. Esta 
Tabela 3 - Caracterização hidrodinâmica e análise da produtividade adaptado de Struckmeir e Margat (1995

\begin{tabular}{|c|c|c|c|}
\hline $\mathrm{Q} / \mathrm{s}\left(\mathrm{m}^{3} / \mathrm{h} / \mathrm{m}\right)^{*}$ & VAZÃO $\left(\mathrm{m}^{3} / \mathrm{h}\right)$ & PRODUTIVIDADE AQUÍFERA & CLASSE \\
\hline$\geq 4,0$ & $\geq 100$ & $\begin{array}{l}\text { Muito Alta: Fornecimentos de água de importância regional } \\
\text { (abastecimento de cidades e grandes irrigações). Aquíferos } \\
\text { que se destaquem em âmbito nacional. }\end{array}$ & (1) \\
\hline $2,0 \leq \mathrm{Q} / \mathrm{s}<4,0$ & $50 \leq \mathrm{Q}<100$ & $\begin{array}{l}\text { Alta: características semelhantes à classe anterior, contudo } \\
\text { situando-se dentro da média nacional de bons aquíferos. }\end{array}$ & $(2)$ \\
\hline $1,0<\mathrm{Q} / \mathrm{s}<2,0$ & $25 \leq \mathrm{Q}<50$ & $\begin{array}{l}\text { Moderada: Fornecimento de água para abastecimento locais } \\
\text { em pequenas comunidades, irrigação em áreas restritas. }\end{array}$ & (3) \\
\hline $0,4 \leq \mathrm{Q} / \mathrm{s}<1,0$ & $10 \leq \mathrm{Q}<25$ & $\begin{array}{l}\text { Geralmente baixa, porém localmente moderada: } \\
\text { Fornecimentos de água para suprir abastecimentos locais ou } \\
\text { consumo privado. }\end{array}$ & (4) \\
\hline $0,04 \leq \mathrm{Q} / \mathrm{s}<0,4$ & $1 \leq \mathrm{Q}<10$ & $\begin{array}{l}\text { Geralmente muito baixa, porém localmente baixa: } \\
\text { Fornecimentos contínuos dificilmente são garantidos. }\end{array}$ & $(5)$ \\
\hline$<0,04$ & $<1,0$ & $\begin{array}{l}\text { Pouco produtiva ou Não Aquífera: Fornecimentos } \\
\text { insignificantes de água. Abastecimentos restritos ao uso de } \\
\text { bombas manuais. }\end{array}$ & (6) \\
\hline
\end{tabular}

condição é vista em $86,72 \%$ dos resultados de IS para todas as fases analisadas e em todos os pontos amostrais.

Os valores de IS negativos representam uma solução subsaturada, sem condições de formação da fase sólida mineral, esta condição é vista em $13,28 \%$ dos resultados de IS para todas as fases analisadas e em todos os pontos amostrais.

As fases analisadas com base na composição litológica existente na área de estudo foram a goethita $(\mathrm{FeOOH})$ e hematita $\left(\mathrm{Fe}_{2} \mathrm{O}_{3}\right)$ para composição óxido-hidróxido; caulinita $\left(\mathrm{Al}_{2} \mathrm{Si}_{2} \mathrm{O}_{5}(\mathrm{OH})_{4}\right)$ para a composição aluminosa e quartzo $\left(\mathrm{SiO}_{2}\right)$ para a composição silicosa.

Os resultados de IS para as fases analisadas apresentam condições de supersaturação (precipitação) em 100\% nas composição óxidohidróxido para as fases goethita e hematita, indistintamente, tanto no sistema aquífero Barreiras quanto no Cristalino. As condições ambientais e o $\mathrm{pH}$ criam condições necessárias para a precipitação do ferro quando o índice de saturação atinge valores positivos sob a forma de hematita e hidróxidos, aqui representado pela a goethita (Figura 3 ).

A composição aluminosa com a fase caulinita apresenta $66,67 \%$ dos IS em condições de supersaturação (precipitação) e 33,33\% em condições de subsaturação - dissolução (Figura 4). A composição silicosa com fase quartzo apresenta 70,96\% dos IS em condições de supersaturação (precipitação) e 29,04\% em condições de subsaturação (dissolução) quantificando todos os pontos amostrados (Figura 5).

As águas subterrâneas dos poços P01 e P05 são captadas somente do sistema aquífero Barreiras, tendo contribuição somente da Formação Barreiras. Os processos ocorrentes são de supersaturação de ferro nas águas, o que é esperado tendo em vista a composição da formação litológica presente. A fase quartzo e caulinita apresenta subsaturação, podendo esta fase dissolver nesse período e contribuir com o aumento de $\mathrm{pH}$ visto neste ponto no período da condição de dissolução.

As águas subterrâneas dos poços $\mathrm{P} 02, \mathrm{P} 03$, P04, P06, P07, P08 e P10 são captadas tanto do sistema aquífero Barreiras quanto do sistema aquífero Cristalino, tendo contribuição da Formação Barreiras e do Complexo gnáissicomigmatítico. Os processos ocorrentes são de supersaturação de ferro nas águas. A fase quartzo e caulinita apresenta processos de precipitação e dissolução, a depender do $\mathrm{pH}$ e das condições do meio encontrado, como por exemplo a reação devido ao aumento da concentração de bicarbonato no sistema aquífero cristalino, além da mistura de águas.

As águas do poço P09 são captadas do sistema aquífero Cristalino, portanto somente do Complexo gnáissico-migmatítico. Estas águas são de supersaturação quanto ao equilíbrio da fase de ferro, e apresenta reações de supersaturação e subsaturação na fase quartzo e caulinita. 
Tabela 4 - Índices de saturação (IS) nas águas subterrâneas dos poços tubulares amostrados para todas as fases analisadas.

\begin{tabular}{|c|c|c|c|c|c|}
\hline POÇO & FASE & IS (fev/18) & IS (jun/18) & IS (dez/18) & IS (fev/19) \\
\hline \multirow{4}{*}{ P01 } & Goethita & 8,69 & N.C. & 5,42 & N.C. \\
\hline & Hematita & 19,39 & N.C. & 0,12 & N.C. \\
\hline & Quartzo & 0,61 & N.C. & $-1,19$ & N.C. \\
\hline & Caulinita & S.A & N.C. & $-8,03$ & N.C. \\
\hline \multirow{4}{*}{ P02 } & Goethita & 8,17 & 7,32 & 5,39 & N.C. \\
\hline & Hematita & 18,35 & 16,65 & 12,80 & N.C. \\
\hline & Quartzo & 0,77 & 0,89 & $-0,75$ & N.C. \\
\hline & Caulinita & S.A & 4,82 & $-6,55$ & N.C. \\
\hline \multirow{4}{*}{ P03 } & Goethita & 6,65 & 5,24 & 4,33 & N.C \\
\hline & Hematita & 15,31 & 12,48 & 10,66 & N.C. \\
\hline & Quartzo & 0,21 & 0,27 & 0,15 & N.C. \\
\hline & Caulinita & S.A & 4,89 & 4,17 & N.C. \\
\hline \multirow{4}{*}{ P04 } & Goethita & 4,38 & 5,53 & 2,04 & N.C. \\
\hline & Hematita & 10,77 & 13,06 & 6,09 & N.C. \\
\hline & Quartzo & 0,16 & 0,19 & $-0,01$ & N.C. \\
\hline & Caulinita & S.A & 4,91 & 0,06 & N.C. \\
\hline \multirow{4}{*}{ P05 } & Goethita & 8,11 & 5,22 & 5,36 & 6,11 \\
\hline & Hematita & 18,23 & 12,46 & 12,73 & 14,23 \\
\hline & Quartzo & 0,57 & 0,77 & $-1,03$ & 0,49 \\
\hline & Caulinita & S.A & 6,09 & $-7,27$ & 6,94 \\
\hline \multirow{4}{*}{ P06 } & Goethita & 7,16 & 4,63 & 4,24 & N.C. \\
\hline & Hematita & 16,33 & 11,27 & 10,50 & N.C. \\
\hline & Quartzo & 0,43 & 0,39 & 0,34 & N.C. \\
\hline & Caulinita & S.A & 3,60 & 4,33 & N.C. \\
\hline \multirow{4}{*}{ P07 } & Goethita & 5,50 & 6,24 & 7,99 & N.C. \\
\hline & Hematita & 13,02 & 14,49 & 17,99 & N.C. \\
\hline & Quartzo & 0,31 & 0,46 & 0,12 & N.C. \\
\hline & Caulinita & S.A & 4,84 & 3,23 & N.C. \\
\hline \multirow{4}{*}{ P08 } & Goethita & 8,51 & 6,40 & 5,08 & N.C. \\
\hline & Hematita & 19,04 & 14,81 & 12,17 & N.C. \\
\hline & Quartzo & 0,72 & 0,73 & $-1,20$ & N.C. \\
\hline & Caulinita & S.A & 5,13 & $-8,17$ & N.C. \\
\hline \multirow{4}{*}{ P09 } & Goethita & 4,63 & 5,16 & 5,67 & 8,03 \\
\hline & Hematita & 11,27 & 12,33 & 13,35 & 18,06 \\
\hline & Quartzo & 0,94 & 0,97 & $-1,07$ & 0,57 \\
\hline & Caulinita & S.A & 4,89 & $-8,09$ & 2,93 \\
\hline \multirow{4}{*}{ P10 } & Goethita & 5,72 & 5,23 & 5,23 & N.C. \\
\hline & Hematita & 13,44 & 12,47 & 12,47 & N.C. \\
\hline & Quartzo & $-1,03$ & $-0,94$ & $-0,99$ & N.C. \\
\hline & Caulinita & S.A & $-7,46$ & $-7,46$ & N.C. \\
\hline
\end{tabular}

N.C.: amostra não coletada; S.A: sem análise para a fase. Observação: tendo em vista a anomalia de ferro ocorrida na amostra P05 devido a danos físicos no poço, este foi modelado com uma concentração 10 vezes menor que a concentração de ferro analisada. 


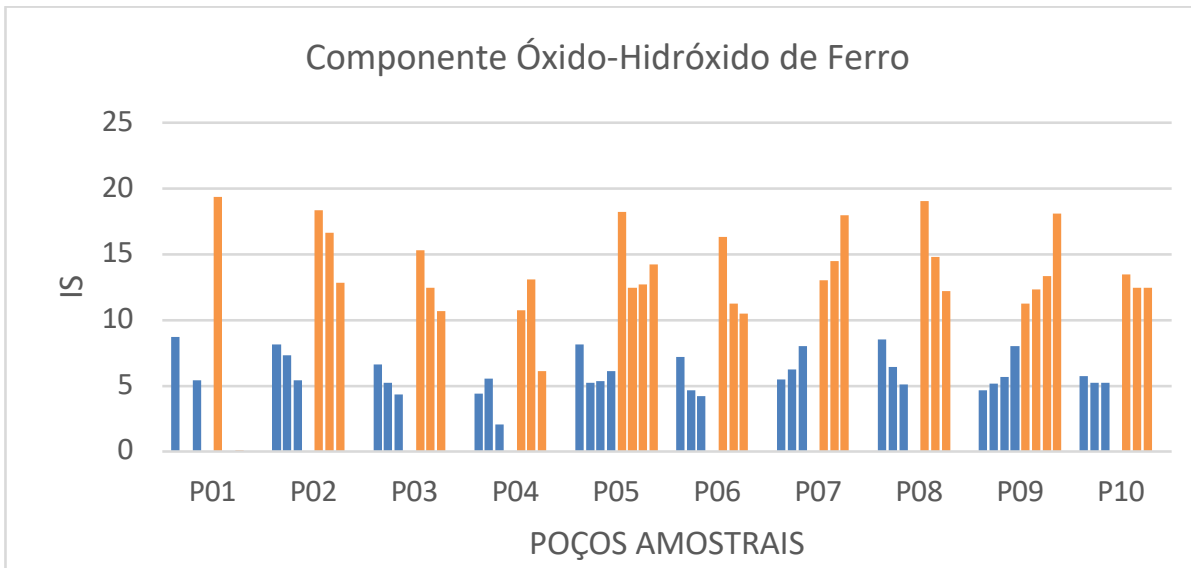

a Goethita fev/18 Goethita jun/18 Goethita dez/18 a Goethita fev/19

Hematita fev/18 $\square$ Hematita jun/18 $\square$ Hematita dez/18 $\square$ Hematita fev/19

Figura 3

Índices de saturação da componente óxido-hidróxido de ferro em todo o período de monitoramento.

\section{Componente Aluminosa}

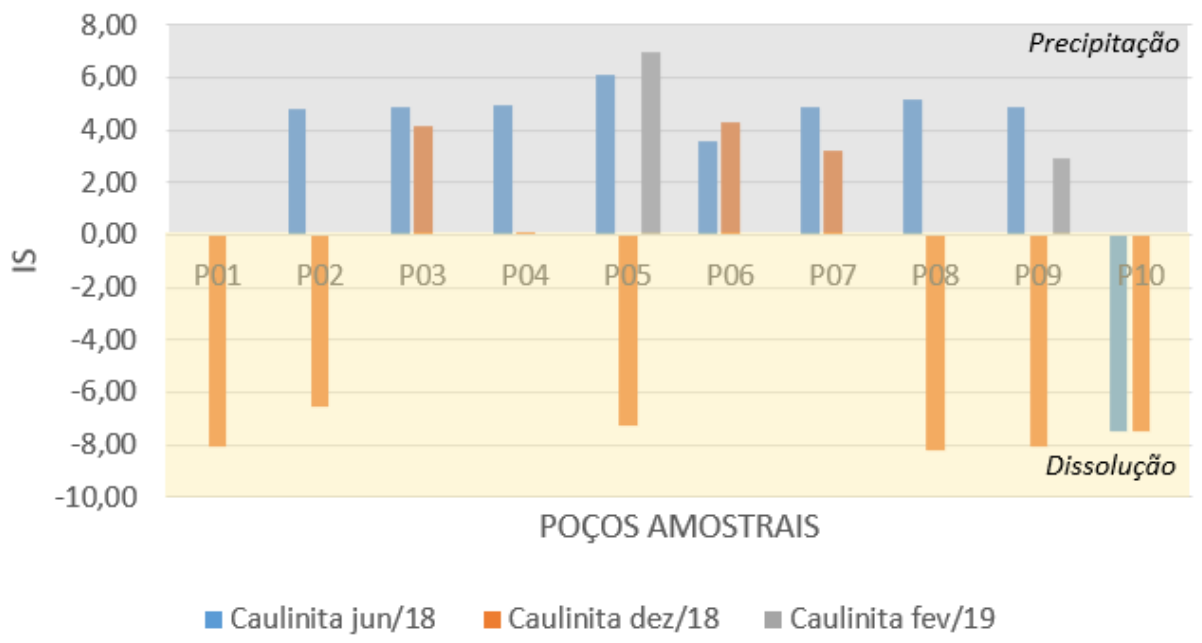

Figura 4 Índices de saturação da componente aluminosa em todo o período de monitoramento

Componente Silicosa

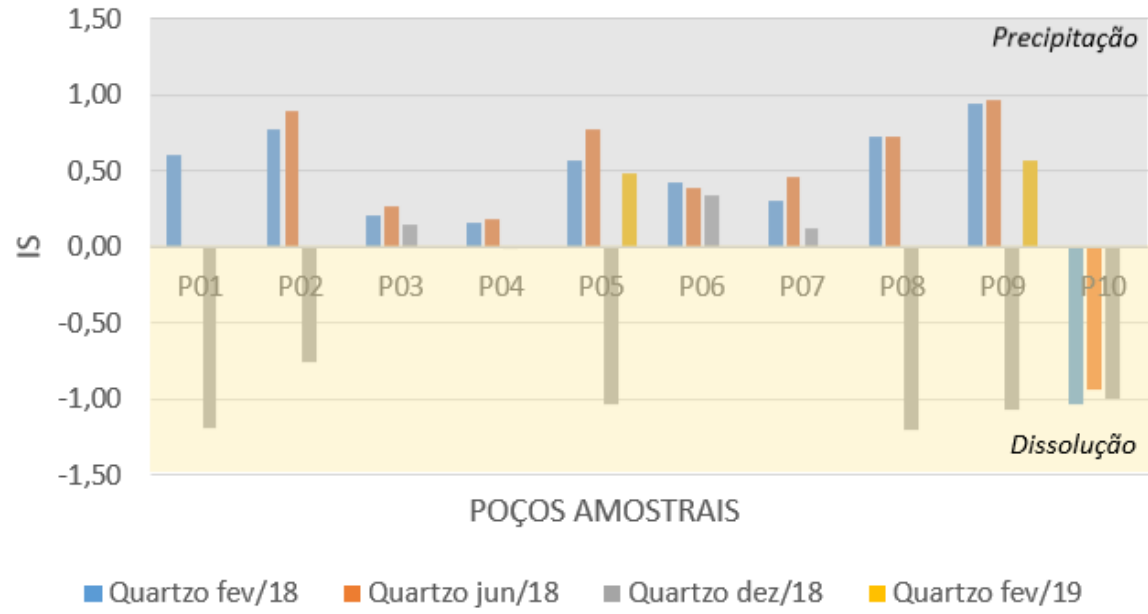

Figura 5 Índices de saturação da componente silicosa em todo o período de monitoramento. 


\section{CONCLUSÕES}

As águas são dominantemente cloretadassódica, doces, com baixo teor em nitrato e com turbidez um pouco acima do recomendado para águas potáveis. Quanto aos metais pesados, dois poços apresentaram níveis de $\mathrm{Pb}$ acima do VMP e, portanto, sugere-se a continuação do monitoramento da qualidade da água do aquífero, principalmente para esses poços. $\mathrm{O}$ $\mathrm{Zn}$, micronutriente, está presente em concentrações traço, e foram identificadas águas alcalinas, como as do poço P01, P02, P09 e P10, as quais são recomendadas na literatura médica e de marketing (águas envasadas) como sendo benéficas no tratamento de problemas gastro-intestinal, hipertensão, diabetes e cancro. A análise dos poços estudados classificou a produtividade aquífera de baixa (classe 4) a muita baixa (classe 5) com base na vazão, e de pouco produtiva (classe 6) a moderada (classe 3), com base na capacidade específica. Há uma variação grande da classificação da produtividade aquífera com base em cada parâmetro classificatório em questão, segundo os quais o mesmo aquífero pode ocorrer em diferentes classes de produtividades. Para isso, faz-se necessário o acréscimo do número de poços amostrais no estudo bem como a utilização de outros parâmetros adicionais como: permeabilidade dos corpos rochosos do meio, valores de condutividade hidráulica e

\section{REFERÊNCIAS}

ABBOTT, B. W.; BISHOP, K.; ZARNETSKE, J. P.; MINAUDO, C.; CHAPIN II, F. S.; DRAUSE, S.; HANNAH, D. M.; CONNER, L.; ELLISON, D.; GODSEY, S. E.; PLONT, S.; MARÇAIS, J.; KOLBE, T.; HUEBNER, A.; FREI, R. J.; HAMPTON, T.; GU, S.; BUHMAN, M.; SAYEDI, S. S.; URSACHE, O.; CHAPIN, M.; HENDERSON, K. D; PINAY, G. (2019) Human domination of the global water cycle absent from depictions and perceptions. Nat. Geosci. 12:533540.

AMINOT, A.; KÉROUEL, R. (2004). Dissolved organic carbon, nitrogen and phosphorus in the N-E Atlantic and the N-W Mediterranean with particular reference to non-refractory fractions and degradation. Deep Sea Research Part I: Oceanographic Research Papers. 51. 1975-1999. 10.1016/j.dsr.2004.07.016.

AMINOT, A.; CHAUSSEPIED, M. (1983) Manuel des analyses chimiques en milieu marin. CNEXO, Brest. França. Vol 1 395p.

APHA (2012) Standard Methods For The Examina- valores de recarga. O modelo geoquímico proposto da água subterrânea é de supersaturação de ferro das águas subterrâneas das coberturas da Formação Barreiras e embasamento cristalino indistintamente, observado na concentração de ferro total quantificada nos poços amostrais, oriundas dos sedimentos da Formação Barreiras. A composição aluminosa e silicosa apresenta condições de supersaturação (precipitação) em sua maioria, e de subsaturação (dissolução), refletindo a concentração quantificada de alumínio e quartzo, presente tanto nos argilominerais aluminosos da Formação Barreiras quanto na litologia do embasamento cristalino.

O estudo permitiu a caracterização do cenário atual sobre as potencialidades desse recurso hídrico, permitindo identificar e localizar as regiões com potencial para o suprimento de água e as regiões cujas potencialidades estão comprometidas por fontes de contaminação das águas existentes no Campus, como laboratórios químicos. Esses resultados nortearão as definições das propostas de manejo, visando à proteção das reservas estratégicas ao abastecimento das demandas atuais e futuras, tendo em vista a suma importância do uso do recurso hídrico para a comunidade.

tion Of Water And Wastewater, 22nd Ed.: American Public Health Association, American Water Works Association, Water Environment Federation. Washington, DC.

APRILE, A.; DE BELLIS, L. (2020) Editorial for Special Issue "Heavy Metal Accumulation, Toxicity, and Detoxification in Plants". Int. J. of Molecular Sciences. 21:4103 http://doi.org/10.3390/ijms21114103.

ARPAT - AGENZIA REGIONALE PER LA PROTEZIONE AMBIENTALE DELLA TOSCANA DIPARTIMENTO DI GROSSETO (2007) Determinazione delle concentrazioni elementari nelle acque del sistema MerseCampiano, 73 p.

ASSOCIAÇÃO PORTUGUESA DE DRENAGENS DAS ÁGUAS (APDA) (2012) Comissão Especializada da Qualidade da Água em 2012/12/12. Disponível em: https://www.apda.pt/site/upload/FT-QI-10$\% 20$ Dureza\%20total.pdf. Acesso em: $16 / 09 / 2020$. 
BARTRAM, J. (Ed) (2009) Calcium and Magnesium in Drinking-water: Public Health Significance. World Health Organization.

BRANDÃO, R.L (1995) Sistema de Informações para Gestão e Administração Territorial da Região Metropolitana de Fortaleza - Projeto SINFOR: Diagnóstico Geoambiental e os Principais Problemas de Ocupação do Meio Físico da Região Metropolitana de Fortaleza. $1^{\mathrm{a}}$ edição. Fortaleza/CE: SER/REFO/CPRM. vol. 1, $105 \mathrm{p}$.

BURAZER M., ZITKO V., RADAKOVIC D., PARAREZANOVIC M. (2010) Using geophysical methods to define the attitude and extension of water-bearing strata in Miocene sediments of Pannonian Basin. J. of Appl Geophy. 72(4):242-253

http://doi.org/10.1016/j.jappgeo.2010.10.002.

CONSELHO NACIONAL DO MEIO AMBIENTE

- CONAMA - Resolução N³96/2008, de 03 de abril de 2008. Dispõe sobre a classificação e diretrizes ambientais para o enquadramento das águas subterrâneas e dá outras providências. Publicação DOU n ${ }^{\circ}$ 66, de 07/04/2008, 66-68.

CAVALCANTE, I. N. (1998) Fundamentos Hidrogeológicos para a Gestão Integrada de Recursos Hídricos na Região Metropolitana de Fortaleza, Estado do Ceará. 1998. 153f. Tese de Doutorado - Instituto de Geociências, Universidade de São Paulo, São Paulo.

CETESB - Companhia Ambiental do Estado de São Paulo (2016) Relatório da Qualiadde das Águas Interiores do estado de Snao Paulo. Apêndice D - Índices de Qualidade da Água. 32p.

CHIUVE, S. E.; SUN Q.; CURHAN, G. C., TAYLOR, E.N.; SPIEGELMAN D.; WILLETT, W.C.; MANSON, J.E.; REXRODE, K.M.; ALBERT, C.M.,. (2013) Dietary and plasma magnesium and risk of coronary heart disease among women. J. Am. Heart Assoc. 2:e00114.

COOK, C.; BAKKER, K. (2010) Water security: debating an emerging paradigm. Global Environ. Chang. 22:94-102.

DEL GOBBO L. C.; IMAMURA F.; WU J. H.; DE OLIVEIRA O. M. C.; CHIUVE S. E.; MOZAFFARIAN D. (2013) Circulating and dietary magnesium and risk of cardiovascular disease: a systematic review and meta-analysis of prospective studies. Am. J. Clin. Nutr. 98(1):160-173

DIÁRIO DA REPÚBLICA (2017) $1 .^{\mathrm{a}}$ série - N. ${ }^{\circ}$ 235 - 7 de dezembro de 2017. Decreto-Lei n. $^{\circ}$ 152/2017de 7 de dezembro. Acesso disponível em: https://dre.pt/application/file/114311249. Acesso em: 16/09/2020.

DIAZ D.; MAKSYMOWICZ A.; VARGAS G.; VERA E.; CONTRERAS-REYES E.; REBOLLEDO S. (2014) Exploring the shallow structure of the San Ramón thrust fault in Santiago, Chile $\left(\sim 33.5^{\circ} \mathrm{S}\right)$, using active seismic and electric methods. Solid Earth, 5:837-849. http://doi.org/10.5194/se-5-837-2014.

ECAN (2019) Nitrate in waterways - What's the story?. Environment Canterbury Regional Council. Disponível em: https://ecan.govt.nz/get-involved/news-andevents/2019/nitrate-in-waterways-whats-thestory. Acesso em 20/11/2019

FENZL, N. (1986) Introdução à hidrogeoquímica. EdUFPA. Belém:. ISBN 85-247-0023-8.

FUNCEME (2019) Médias mensais de precipitação pluviométrica e temperatura em Fortaleza -CE. Histórico da FUNCEME. Site disponível em: http://www.funceme.br/pcd/graficos/12. Acesso em: 08/04/2019.

GOMES, D. F. (2005) Estudo hidroquímico, isotópico e da dinâmica do nível estático das águas subterrâneas e superficiais da região de Limoeiro do Norte - Baixo Jaguaribe. Tese de Doutorado, Universidade Federal do Ceará, 218 páginas.

GOMES, M. DA C. R. (2008) Aspectos Hidrogeológicos do Município de Fortaleza Ceará. Especialização em Gestão Hídrica da Universidade Federal do Pará. Departamento de Geologia da Universidade Federal do Pará. Belém/PA. 82p.

HIRATA, R.; SUHOGUSOFF, A.V. (2019) How much do we know about the groundwater quality and its impact on Brazilian society today? Acta Limnol. Bras., 31:e109.

NASCIMENTO, A. de M.; BARBOSA, J. S. F., (2005) Qualidade da água do aquífero no alto cristalino de Salvador, Bacia do Rio Lucaia, Salvador, Bahia. Rev. Bras. Geoc. 35(4):144158.

IOP Conference Series: Materials Science and Engineering (2019) Sustainable and Integrated Engineering International Conference 2019 (SIE 2019) 8-9 December, Volume 884, The Everly Putrajaya, Putrajaya, Malaysia.

MELLO K.; TANIWAKI R. H.; DE PAULA, F. R.; , VALENTE, R. A.; RANDHIR, T. O.; MACEDO, D. R.; LEAL, C. G.; RODRIGUES, B. R.; HUGHES, R. M. (2020) Multiscale land use impacts on water quality: Assessment, planning, and future perspectives in Brazil, $J$. Env. Manage., 270:110879, https://doi.org/10.1016/j.jenvman.110879.

LUCENA L. R. F. (2005) Implicação $d a$ compartimentação estrutural no Aquífero Barreiras na área da bacia do Rio Pirangi-RN. Tese de Doutorado, Universidade Federal do Paraná-UFPR, 151

LUOMA, S., RAINBOW, P. (2008) Metal Contamination in Aquatic Environments: Science and Lateral Management. Cambridge University Press, New York.

MONARCA, S.; DONATO, F.; ZERBINI, I.; CALDERON, R.; CRAUN, G. (2006) Review of Epidemiological Studies on Drinking Water Hardness and Cardiovascular Diseases. Eur. J. 
Cardiov. Prev. $\quad R . \quad 13: 495-506$. https://10.1097/01.hjr.0000214608.99113.5c.

MOMOT, O.; SYNZYNYS, B. (2005) Toxic Aluminium and Heavy Metals in Groundwater of Middle Russia: Health Risk Assessment. Int. J. Environ. Res. Public Health. 2:214-218. https://10.3390/ijerph2005020003.

MOURA I. M.DE (2013) Estudos das águas da bacia hidrográfica do rio Banabuiú no trecho entre Quixeramobim e Banabuiú - Ceará, Brasil. 2013. 243 f. Tese de Doutorado. Universidade Federal do Ceará, Fortaleza-CE.

NASCIMENTO, A. DE M. E BARBOSA, J. S. F. (2005) Qualidade da água do aquífero no alto cristalino de Salvador, Bacia do Rio Lucaia, Salvador, Bahia. Rev. Bras. de Geoc. 35:543-550

OMS, Organização Mundial da Saúde (2005) Nutrients in Drinking Water. World Health Organization, Geneva, 186 pp. Disponóvel em : http://www.who.int/water_sanitation_health/dw $\mathrm{q} /$ nutrientsindw/en/index.html. Acesso em 16/09/2020

OTTAVIANI, M.; ACHENE L.; FERRETTI E.; LUCENTINI L. (2007) La durezza dell'acqua destinata al consumo umano: riflessi sulla salute umana. Not Ist Super Sanità 20(3):3-6 https://www.physico.eu/pdf/notiziario-issdurezza-acqua.pdf

PILlI A., SAPIGNI M., ZUPPI G. M. (2012) Karstic and alluvial aquifers: conceptual model for the plain - Prealps system (northeastern Italy). J. Hydrol. 464-465:94-106 http://dx.doi.org/10.1016/j.jhydrol.2012.06.049.

QU X. L.; ALVAREZ P. J. J.; LI Q. L. (2013) Applications of nanotechnology in water and wastewater treatment. Water Res 47(12):39313946.

RIBEIRO, J. A. P. (2001) Características Hidrogeológicas e Hidroquímicas da faixa costeira leste da região metropolitana de Fortaleza - Ceará. Dissertação de mestrado. Universidade Federal do Ceará. 122p.

RICHETER, B. C.; KREITLER, C. W. (1993) Geochemical Techniques for Identification Sources of Ground-Water Salinization. C. K. Smoley, Boca Raton, FL 33431.

RONDEAU, V.; JACQMIN-GADDA H.; COMMENGES, D.; HELMER C.; DARTIGUES, J.F. (2009) Aluminium and Silica in Driking Water and the Risk of Alzheimer's
Disease or Cognitive Decline: Finding From 15Year Follow-up of the PAQUID Cohort. Am. J. Epidemiol. 169(4):489- 496.

https//:doi: 10.1093/aje/kwn348

ROSANOFF A. (2013) Changing crop magnesium concentrations: impact on human health. Plant Soil. 368:139-153

ROSE A. W.; HAWKES H. E.; WEBB, J. S. (1979) Geochemistry in Mineral Exploration. Academic Press. London 2nd ed. v. 117, 663 p. ISBN 012 5962509 ,

SHUKLA, S.; SAXENA, A. (2020) Sources and leaching of nitrate contamination in groundwater. Curr. Sci. 118:883-891. http://doi.org/10.18520/cs/v118/i6/883-891.

STRUCKMEIER, W. F.; MARGAT, J. (1995) Hydrogeological maps: A guide and a standard legend. Hannover: International Association of Hydrogeologists, 177 p. - International Contributions to Hydrogeology vol. 17.

THOMAS, M. P. (2010) Calcium and Magnesium in Drinking-water: Public Health Significance, Int. J. of Environ. Stud. 67(4):612-613, http://doi.org/10.1080/00207230903208415

TORQUATO, J.R.F.; SIDRIM, A.C.G.; MARANHÃO, C.M.L., PARENTE, C.V., NOGUEIRA NETO, J.A., ANDRADE FILHO, J.F., SOUZA, J.V., SOUZA, M.J.N., ARTHAUD, M.H. (1989) Granitóides do Ceará. Região de Quixadá-Solonópole. Revista de Geologia 2:1-143.

TUNDISI, J.; MATSUMURA-TUNDISI, T.; CIMINELLI, V.; BARBOSA, F. (2015) Water availability, water quality water governance: the future ahead. Proceedings of the International Association of Hydrological Sciences. 366. 7579. 10.5194/PIAHS-366-75-2015.

VAL, A. L.; BICUDO, E. M.; BICUDO, D. C.; PUJONI, D. G. F.; SPILKI, F. R.; NOGUEIRA, I. S; HESPANHOL, I.; CIRILO, J. A.; TUNDISI, J. G.; VAL, P.; HIRATA, R.; FELICIANO, S. M.; AZEVEDO, S. M. F. O.; CRESTANA, S.; CIMINELLI, V. S. T. (2019) Water quality in Brazil. Water Quality in the Americas: Risks and Opportunities. IANASIAP, Regional Network Academies of Science, México City 104-128.

VILAGINÈS, R. (2003) Eau, environnement et santé publique: Introduction à l'hydrologie. Tec \& Doc Lavoisier Ed. 2. Ed., 198 pp. 


\section{ANEXO}

Valores dos parâmetros analisados nas amostras de água subterrânea no setor noroeste da Região Metropolitana de Fortaleza, no Campus Universitário do Pici. (VMP: valor máximo permitido, N.C.: não coletado, $\bar{x}_{\text {mensal: média }}$ mensal - (média aritmética).

Tabela A1 - Valores de $\mathrm{pH}$

\begin{tabular}{cccccccccccc}
\hline & P01 & P02 & P03 & P04 & P05 & P06 & P07 & P08 & P09 & P10 & $\overline{\boldsymbol{x}}_{\text {mensal }}$ \\
\hline FEV/18 & 7,92 & 7,70 & 6,76 & 5,98 & 7,09 & 6,76 & 6,47 & 8,07 & 5,99 & 8,66 & 7,14 \\
JUN/18 & N.C & 7,25 & 6,37 & 6,47 & 6,45 & 5,96 & 6,74 & 6,86 & 6,07 & 9,03 & 6,80 \\
DEZ/18 & 8,76 & 8,69 & 6,14 & 5,27 & 8,48 & 6,06 & 7,30 & 8,63 & 8,64 & 8,45 & 7,64 \\
FEV/19 & N.C & N.C & N.C & N.C & 6,53 & N.C & N.C & N.C & 7,88 & N.C & 7,21 \\
SET/19 & 7,30 & 7,05 & 5,34 & 5,33 & N.C. & 5,51 & N.C. & 7,75 & 8,12 & 8,91 & 6,91 \\
\hline
\end{tabular}

Tabela A2 - Valores de Condutividade Elétrica $(\mathrm{mS} / \mathrm{cm})$

\begin{tabular}{|c|c|c|c|c|c|c|c|c|c|c|c|}
\hline & P01 & P02 & P03 & P04 & P05 & P06 & P07 & P08 & P09 & P10 & $\overline{\boldsymbol{x}}_{\text {mensal }}$ \\
\hline $\mathrm{FEV} / 18$ & 392,0 & 1422,0 & 279,0 & 161,0 & 512,0 & 127,0 & 334,30 & 869,0 & 323,0 & 1331,0 & 575,0 \\
\hline JUN/18 & N.C. & 1391,0 & 245,4 & 212,1 & 1527,0 & 117,9 & 674,9 & 1106,0 & 396,1 & 1704,0 & 816,4 \\
\hline DEZ/18 & 700,8 & 1429,0 & 329,3 & 188,4 & 1287,0 & 153,3 & 331,4 & 1122,0 & 1918,0 & 1542,0 & 900,1 \\
\hline $\mathrm{FEV} / 19$ & N.C. & N.C. & N.C. & N.C. & 1343,0 & N.C. & N.C. & N.C. & 1457,0 & N.C. & 1400,0 \\
\hline SET/19 & 908,7 & 1199,0 & 229,7 & 303,8 & N.C. & 104,8 & N.C. & 1020,0 & 2584,0 & 1625,0 & 996,9 \\
\hline & P01 & P02 & P03 & P04 & P05 & P06 & P07 & P08 & P09 & P10 & $\overline{\boldsymbol{x}}_{\text {mensal }}$ \\
\hline $\mathrm{FEV} / 18$ & 372 & 1150 & 215 & 129 & 386 & 110 & 215 & 815 & 317 & 960 & 467 \\
\hline JUN/18 & N.C & 955 & 119 & 124 & 998 & 97 & 356 & 853 & 237 & 1122 & 416 \\
\hline $\mathrm{DEZ} / 18$ & 539 & 797 & 130 & 80 & 740 & 74 & 170 & 766 & 1166 & 919 & 538 \\
\hline $\mathrm{FEV} / 19$ & N.C. & N.C. & N.C. & N.C. & 804 & N.C. & N.C. & N.C. & 1116 & N.C. & 960 \\
\hline
\end{tabular}

Tabela A4 - Valores de Alcalinidade Total (mg/L)

\begin{tabular}{lccccccccccc}
\hline & P01 & P02 & P03 & P04 & P05 & P06 & P07 & P08 & P09 & P10 & $\overline{\boldsymbol{x}}_{\text {mensal }}$ \\
\hline FEV/18 & 195,9 & 385,8 & 12,1 & 4,0 & 90,9 & 10,1 & 22,2 & 391,9 & 97,0 & 351,5 & 156,1 \\
JUN/18 & N.C. & 296,9 & 10,1 & 20,2 & 284,8 & 18,2 & 64,6 & 395,9 & 99,0 & 385,8 & 175,1 \\
DEZ/18 & 319,2 & 230,3 & 4,0 & 2,0 & 222,2 & 2,0 & 16,2 & 395,9 & 565,6 & 319,2 & 207,7 \\
FEV $/ 19$ & N.C. & N.C. & N.C. & N.C. & 230,3 & N.C. & N.C. & N.C. & 515,1 & N.C. & 372,7 \\
\hline
\end{tabular}

Tabela A5 - Valores de Nitrato (mg/L) VMP: $10 \mathrm{mg} / \mathrm{L}$

\begin{tabular}{rccccccccccc}
\hline & P01 & P02 & P03 & P04 & P05 & P06 & P07 & P08 & P09 & P10 & $\overline{\boldsymbol{x}}_{\text {mensal }}$ \\
\hline FEV/18 & $<0,1$ & $<0,1$ & 12,5 & 6,6 & 1,2 & 6,8 & 1,3 & $<0,1$ & $<0,1$ & 0,5 & 2,9 \\
JUN/18 & N.C & 3,4 & 5,8 & 4,3 & 0,3 & 0,3 & 0,5 & 0 & 0,1 & 0,3 & 1,7 \\
DEZ/18 & 0,1 & 2,3 & 6,4 & 2,7 & 0,9 & 4,2 & 0,7 & 0,2 & 0,2 & 0,1 & 1,8 \\
FEV $/ 19$ & N.C. & N.C. & N.C. & N.C. & 0,4 & N.C. & N.C. & N.C. & 0,5 & N.C. & 0,5 \\
\hline
\end{tabular}

Tabela A6 - Valores de Sódio (mg/L) VMP: 200 mg/L

\begin{tabular}{|c|c|c|c|c|c|c|c|c|c|c|c|}
\hline & P01 & P02 & P03 & P04 & P05 & P06 & P07 & P08 & P09 & P10 & $\overline{\boldsymbol{x}}_{\text {mensal }}$ \\
\hline $\mathrm{FEV} / 18$ & 81,6 & 198,7 & 42,0 & 29,0 & 76,8 & 27,0 & 63,9 & 179,3 & 52,6 & 195,5 & 94,6 \\
\hline JUN/18 & N.C. & 208,1 & 31,9 & 30,4 & 193,4 & 19,0 & 93,1 & 211,8 & 52,2 & 319,9 & 129,4 \\
\hline DEZ/18 & 123,1 & 216,9 & 41,4 & 25,0 & 137,7 & 23,1 & 46,9 & 224,2 & 253,5 & 216,9 & 130,8 \\
\hline $\mathrm{FEV} / 19$ & 81,6 & 198,7 & 42,0 & 29,0 & 76,8 & 27,0 & 63,9 & 179,3 & 52,6 & 195,5 & 94,6 \\
\hline
\end{tabular}

Tabela A7 - Valores de Potássio (mg/L)

\begin{tabular}{lccccccccccc}
\hline & P01 & P02 & P03 & P04 & P05 & P06 & P07 & P08 & P09 & P10 & $\overline{\boldsymbol{X}}_{\text {mensal }}$ \\
\hline FEV/18 & 7,5 & 17,5 & 6,2 & 3,1 & 7,5 & 5,1 & 4,8 & 12,4 & 6,2 & 17,0 & 8,7 \\
JUN/18 & N.C & 13,4 & 3,9 & 3,3 & 17,0 & 5,1 & 7,7 & 13,1 & 10,1 & 20,3 & 10,4 \\
DEZ/18 & 12,8 & 18,8 & 5,5 & 3,8 & 17,8 & 5,5 & 4,7 & 15,4 & 35,7 & 22,1 & 14,2 \\
FEV/19 & 7,5 & 17,5 & 6,2 & 3,1 & 7,5 & 5,1 & 4,8 & 12,4 & 6,2 & 17,0 & 8,7 \\
\hline
\end{tabular}

Tabela A8 - Valores de Dureza Total VMP: 500 mg/L

\begin{tabular}{lccccccccccc}
\hline & P01 & P02 & P03 & P04 & P05 & P06 & P07 & P08 & P09 & P10 & $\overline{\boldsymbol{x}}_{\text {mensal }}$ \\
\hline FEV/18 & 54 & 256 & 80 & 30 & 96 & 18 & 36 & 42 & 76 & 236 & 92 \\
JUN/18 & N.C & 192 & 38 & 36 & 280 & 22 & 70 & 48 & 76 & 280 & 116 \\
DEZ/18 & 70 & 18 & 40 & 22 & 204 & 10 & 30 & 52 & 288 & 204 & 111 \\
FEV/19 & N.C. & N.C. & N.C. & N.C. & 216 & N.C. & N.C. & N.C. & 274 & N.C. & 245 \\
\hline
\end{tabular}


Tabela A9 - Valores de Cloreto (mg/L) VMP: $250 \mathrm{mg} / \mathrm{L}$

\begin{tabular}{cccccccccccc}
\hline & P01 & P02 & P03 & P04 & P05 & P06 & P07 & P08 & P09 & P10 & $\overline{\boldsymbol{x}}_{\text {mensal }}$ \\
\hline FEV/18 & 26,3 & 270,4 & 67,0 & 45,0 & 112,5 & 29,0 & 86,1 & 86,1 & 55,0 & 280,0 & 105,7 \\
JUN/18 & N.C & 212,5 & 43,1 & 42,1 & 273,1 & 23,0 & 136,9 & 89,0 & 58,4 & 306,3 & 131,7 \\
DEZ/18 & 23,0 & 209,9 & 59,0 & 38,0 & 243,9 & 25,0 & 76,0 & 100,0 & 175,9 & 265,9 & 121,7 \\
FEV/19 & N.C. & N.C. & N.C. & N.C. & 229,9 & N.C. & N.C. & N.C. & 138,0 & N.C. & 184,0 \\
\hline
\end{tabular}

Tabela A10 - Valores de Fluoreto (mg/L) VMP: $1,5 \mathrm{mg} / \mathrm{L}$

\begin{tabular}{lllllllllllc}
\hline & P01 & P02 & P03 & P04 & P05 & P06 & P07 & P08 & P09 & P10 & $\overline{\boldsymbol{x}}_{\text {mensal }}$ \\
\hline FEV/18 & 1,00 & 0,20 & 0,20 & 0,20 & 0,30 & 0,20 & 0,20 & 0,50 & 0,60 & 0,50 & 0,60 \\
JUN/18 & N.C & 0,50 & 0,30 & 0,30 & 0,40 & 0,30 & 0,30 & 0,70 & 0,40 & 0,40 & 0,40 \\
DEZ/18 & 0,60 & 0,10 & 0,10 & 0,08 & 0,20 & 0,10 & 0,10 & 0,40 & 0,10 & 0,10 & 0,20 \\
FEV/19 & N.C. & N.C. & N.C. & N.C. & 0,30 & N.C. & N.C. & N.C. & 0,40 & N.C. & 0,35 \\
\hline
\end{tabular}

Tabela A11 - Valores de Sílica (mg/L)

\begin{tabular}{lccccccccccc}
\hline & P01 & P02 & P03 & P04 & P05 & P06 & P07 & P08 & P09 & P10 & $\overline{\boldsymbol{x}}_{\text {mensal }}$ \\
\hline FEV/18 & 26,1 & 37,3 & 10,2 & 9,0 & 23,1 & 16,8 & 12,7 & 33,4 & 54,5 & 37,2 & 26,0 \\
JUN/18 & N.C & 49,0 & 11,8 & 9,7 & 37,0 & 15,3 & 18,3 & 34,0 & 58,5 & 47,2 & 31,2 \\
DEZ/18 & 29,4 & 39,7 & 8,9 & 6,2 & 25,4 & 13,8 & 8,3 & 33,3 & 55,2 & 37,2 & 25,7 \\
FEV/19 & N.C. & N.C. & N.C. & N.C. & 19,2 & N.C. & N.C. & N.C. & 23,3 & N.C. & - \\
\hline
\end{tabular}

Tabela A12 - Valores de Ferro Total (mg/L) VPM: 0,3 mg/L

\begin{tabular}{lllllllllllc}
\hline & P01 & P02 & P03 & P04 & P05 & P06 & P07 & P08 & P09 & P10 & $\overline{\boldsymbol{x}}_{\text {mensal }}$ \\
\hline FEV/18 & 0,90 & 0,30 & 0,20 & 0,20 & 1,00 & 0,60 & 0,20 & 0,60 & 1,70 & 0,30 & 0,60 \\
JUN/18 & N.C & 0,10 & 0,10 & 0,10 & 0,10 & 0,40 & 0,10 & 0,10 & 0,80 & 0,10 & 0,20 \\
DEZ/18 & 0,17 & 0,08 & 0,06 & 0,12 & 0,09 & 0,08 & 0,31 & 0,09 & 0,43 & 0,09 & 0,20 \\
FEV/19 & N.C. & N.C. & N.C. & N.C. & 4,00 & N.C. & N.C. & N.C. & 0,20 & N.C. & - \\
\hline
\end{tabular}

Tabela A13 - Valores de Turbidez (NTU) VPM: 5,0 NTU

\begin{tabular}{cccccccccccc}
\hline & P01 & P02 & P03 & P04 & P05 & P06 & P07 & P08 & P09 & P10 & $\overline{\boldsymbol{x}}_{\text {mensal }}$ \\
\hline FEV/18 & 19,0 & 13,0 & 14,0 & 13,0 & 16,0 & 16,0 & 13,0 & 14,0 & 14,0 & 19,0 & 15,1 \\
JUN $/ 18$ & N.C & 12,4 & 13,0 & 12,4 & 7,3 & 17,9 & 11,1 & 6,5 & 17,3 & 13 & 12,3 \\
DEZ/18 & 6,1 & 4,7 & 4,7 & 6,3 & 5,2 & 5,9 & 7,2 & 4,8 & 9,4 & 6,0 & 6,0 \\
FEV/19 & N.C & N.C & N.C & N.C & 102 & N.C & N.C & N.C & 2,9 & N.C & - \\
\hline
\end{tabular}

Tabela A14 - Valores de Sulfato (mg/L)

\begin{tabular}{lccccccccccc}
\hline & P01 & P02 & P03 & P04 & P05 & P06 & P07 & P08 & P09 & P10 & $\overline{\boldsymbol{x}}_{\text {mensal }}$ \\
\hline FEV $/ 18$ & 0,5 & 86,6 & 0,6 & 0,5 & 22,9 & 2,1 & 5,5 & 13,9 & 9,6 & 23,4 & 16,6 \\
JUN/18 & N.C. & 52 & 0,5 & 0,5 & 51,0 & 0,8 & 1,5 & 8 & 1,1 & 18,6 & 14,9 \\
DEZ/18 & 0,6 & 52,8 & 0,1 & $<0,01$ & 27,3 & 0,1 & 6,2 & 5 & 42,2 & 12,9 & 16,3 \\
FEV/19 & N.C. & N.C. & N.C. & N.C. & 15,1 & N.C. & N.C. & N.C. & 28,7 & N.C. & 21,9 \\
\hline
\end{tabular}

Tabela A15 - Valores de Nitrito (mg/L)

\begin{tabular}{lccccccccccc}
\hline & P01 & P02 & P03 & P04 & P05 & P06 & P07 & P08 & P09 & P10 & $\overline{\boldsymbol{x}}_{\text {mensal }}$ \\
\hline FEV/18 & $<0,01$ & $<0,01$ & $<0,01$ & $<0,01$ & $<0,01$ & $<0,01$ & $<0,01$ & $<0,01$ & $<0,01$ & $<0,01$ & $<0,01$ \\
JUN/18 & N.C & $<0,01$ & $<0,01$ & $<0,01$ & $<0,01$ & $<0,01$ & $<0,01$ & $<0,01$ & $<0,01$ & $<0,01$ & $<0,01$ \\
DEZ/18 & $<0,01$ & 0,03 & $<0,01$ & $<0,01$ & $<0,01$ & $<0,01$ & $<0,01$ & $<0,01$ & $<0,01$ & $<0,01$ & $<0,01$ \\
FEV/19 & N.C. & N.C. & N.C. & N.C. & $<0,01$ & N.C. & N.C. & N.C. & $<0,01$ & N.C. & $<0,01$ \\
\hline
\end{tabular}

Tabela A16 - Valores de Alumínio (mg/L) VPM: 0,20 mg/L

\begin{tabular}{cccccccccccc}
\hline Amostra & P01 & P02 & P03 & P04 & P05 & P06 & P07 & P08 & P09 & P10 & $\overline{\boldsymbol{x}}_{\text {mensal }}$ \\
\hline JUN $/ 18$ & N.C & $<0,02$ & 0,04 & 0,04 & 0,05 & 0,05 & $<0,02$ & $<0,02$ & 0,05 & $<0,02$ & 0,03 \\
DEZ/18 & $<0,02$ & $<0,02$ & 0,02 & $<0,02$ & 0,02 & $<0,02$ & $<0,02$ & $<0,02$ & $<0,02$ & $<0,02$ & 0,02 \\
FEV $/ 19$ & N.C & N.C & N.C & N.C & 0,19 & N.C & N.C & N.C & 0,02 & N.C & 0,11 \\
\hline
\end{tabular}

Tabela A17- Concentração de metais pesados ( $\mu \mathrm{g} / \mathrm{L}$ ) nas águas captadas por poços no campus do Pici, coletadas em SET/2019

\begin{tabular}{|c|c|c|c|c|c|c|c|c|c|c|}
\hline \multicolumn{11}{|c|}{ Poços amostrados } \\
\hline Elemento & P01 & P02 & P03 & P04 & P06 & P08 & P09 & P10 & VMP1 & LD \\
\hline $\mathrm{Ba}$ & 130,9 & 90,0 & 76,6 & 149,8 & 105,3 & 83,7 & 70,1 & 227,6 & 700 & 0,5 \\
\hline $\mathrm{Cr}$ & $<0,5$ & $<0,5$ & $<0,5$ & $<0,5$ & $<0,5$ & $<0,5$ & $<0,5$ & $<0,5$ & 50 & 0,5 \\
\hline $\mathrm{Cu}$ & 0,1 & $<0,5$ & 1,9 & 6,8 & 2,2 & 0,85 & 1,3 & 1,1 & 2.000 & 0,5 \\
\hline $\mathrm{Mn}$ & 31,6 & 11,5 & 5,6 & 7,0 & 4,8 & $<0,5$ & 1,3 & $<0,5$ & 100 & 0,5 \\
\hline $\mathrm{Ni}$ & $<0,5$ & $<0,5$ & $<0,5$ & 1,9 & 1,7 & $<0,5$ & 0,8 & $<0,5$ & 70 & 0,5 \\
\hline $\mathrm{Pb}$ & 8,1 & 14,1 & 2,1 & 3,0 & 4,0 & 9,9 & 18,0 & 135,0 & 10 & 0,5 \\
\hline $\mathrm{Zn}$ & 0,8 & 3,9 & 15,4 & 16,3 & 120,3 & 7,6 & $<0,5$ & $<0,5$ & 5.000 & 0,5 \\
\hline
\end{tabular}

